\title{
IL LIBRO COME MAESTRO: SUFISMO E STORIA DELLA LETTURA NEL MEDIOEVO ISLAMICO
}

\author{
Samuela Pagani
}

\author{
UNIVERSitÀ DEL SALENTO, LECCE
}

Between the end of the 8 th/14th century and the beginning of the 9 th/15th, the literate elites in Yemen and al-Andalus publicly debated the legitimacy and the educational function of Sufi books. In Yemen, where Ibn 'Arabī's 'school' thrived, some jurists urged the ban of his books, while ${ }^{\mathrm{c}} \mathrm{Abd}$ alKarīm al-Ğîli and his associates extolled their educational virtue for Sufi novices. In al-Andalus, the debate focused on whether books could take the place of the master in Sufi education, an issue whose relevance was felt well beyond Sufi circles, prompting Ibn Haldūn to join the discussion. These controversies, even though they were connected to specific local contexts, are significant in a general way because they offer evidence for the spread of private reading among Sufis in the later Middle Ages. To appreciate the historical importance of this, one should ask how far it is new and whether it is limited to Sufism. These two questions are addressed in the first two parts of this article. The first part outlines key changes relating to Sufi literary output in the 12 th and 13th centuries. In particular, it examines the tension between orality and writing within Sufism, and the ways in which the written transmission of mystical knowledge was controlled or repressed. The second part draws attention to shared paradigms of both esoteric and exoteric knowledge as the connection between private reading and innovation, and the preservation of oral symbolism in written transmission. Finally, the third part re-examines the 14 th and 15 th-century debates from the angle of the history of reading in medieval Sufism. The arguments exchanged in these debates bear witnesses to changes in reading practice linked to the shifting relationships between authority and knowledge in Islamic cultural history.

\section{Introduzione}

Tra la fine del VIII/XIV secolo e l'inizio del IX/XV, le élites erudite dell'Andalusia e dello Yemen sono state coinvolte in due animati dibattiti pubblici intorno alla legittimità e alla funzione pedagogica dei libri nel sufismo. In Yemen, dove la scuola di Ibn ${ }^{\mathrm{c}}$ Arabī ebbe in quest'epoca un momento di grande espansione, alcuni giuristi cercarono di far mettere al bando i libri di Ibn ${ }^{c}$ Arabī, mentre ${ }^{c}$ Abd al-Karīm al-Ğî̀ī e altri sufi ne celebrarono il valore formativo e ne promossero la divulgazione. In Andalusia, si discusse se i libri potessero sostituire il maestro nell'educazione dei sufi. L'importanza della questione fu avvertita ben al di là dei circoli sufi, a tal punto da indurre Ibn Haldūn a 
intervenire nel dibattito. Per quanto legate a specifici contesti locali, queste due controversie, sorte negli stessi anni ai due estremi del mondo arabo, sono il segno di una sempre maggiore diffusione della pratica della lettura privata in ambito sufi.

Per cogliere la portata storica di un tale fenomeno, occorre chiedersi in che misura esso costituisca una novità e sia limitato specificamente al sufismo. Le prime due parti di questo studio cercano di rispondere a queste due domande. La prima parte descrive alcune trasformazioni che si sono prodotte nel rapporto con il libro già nel sufismo dei due secoli precedenti ai dibattiti del VIII/XIV-IX/XV secolo, soffermandosi soprattutto sul problema della tensione fra oralità e scrittura all'interno del sufismo e sulle modalità di controllo o di repressione della divulgazione scritta della conoscenza mistica. La seconda parte mette in evidenza alcuni paradigmi comuni alle scienze religiose tradizionali e al sufismo, come il nesso fra lettura privata e innovazione, e la persistenza del simbolismo orale nella trasmissione scritta.

Dopo questo inquadramento generale, la terza parte riprende in esame le controversie del VIII/XIV-IX/XV secolo, cercando di metterne in evidenza l'interesse dal punto di vista della storia della lettura e del ruolo del libro nel sufismo del tardo medioevo. Questi dibattiti mostrano che la possibilità che la lettura privata di un libro sostituisca l'insegnamento orale non è soltanto una prassi più o meno tollerata, ma è un metodo che alcuni autori giustificano anche da un punto di vista teorico. Gli argomenti discussi consentono di vedere in un contesto preciso come il cambiamento nella pratica di lettura si colleghi ai mutevoli rapporti fra autorità e conoscenza nella storia culturale.

\section{Esoterismo e divulgazione nel sufismo fra VI/XII e VIII/XIV secolo}

Il sufismo è un caso particolarmente interessante dell'ambivalenza verso lo scritto nella civiltà arabo-islamica, dove la centralità religiosa del testo sacro e il culto del libro e dell'arte della scrittura coesistono con l'idea che l'insegnamento orale sia più autentico e autorevole dei testi scritti. In generale, il sufismo condivide con le altre scienze religiose musulmane l'idea che l'accesso al testo debba essere controllato da maestri autorizzati a trasmetterlo e a interpretarlo. Nel caso del sufismo, questo principio assume però un'importanza particolare, perché la conoscenza sufi è per definizione riservata a pochi. Pertanto, la possibilità e le condizioni della divulgazione in forma scritta di questa conoscenza hanno costituito un problema centrale sin dalle origini del sufismo. I dibattiti pubblici del VIII/XIV secolo intorno alla validità di una formazione mistica basata esclusivamente sui libri si inseriscono in 
questa problematica generale, che ha assunto in quest'epoca una nuova urgenza in seguito alla fioritura di libri sugli aspetti teorici del sufismo nei due secoli precedenti. In questione non è dunque soltanto la pratica della lettura privata, ma la stessa legittimità della letteratura misticofilosofica, contestata non solo dagli ${ }^{c} u l a m \bar{a}^{3}$ ostili al sufismo, ma anche all'interno del sufismo.

Nella storia del sufismo, il principio dell'esoterismo, vale a dire l'obbligo di tenere il segreto fra chi è degno di riceverlo, distinto dal problema dell''indicibilità' dell'esperienza mistica, ha un valore fondatore. L'opposizione alla divulgazione serve infatti sin dalle origini a contraddistinguere la corrente 'sobria' e 'moderata' del sufismo dalle sue manifestazioni eterodosse. Secondo la tradizione sufi, la 'divulgazione del segreto' (ifša $\bar{a}^{\jmath}$ al-sirr) è stata la causa della rottura di al-Ğunayd (m. 298/910), l'autorità di riferimento della scuola di Baghdad, con al-Hallāğ, già prima che questi fosse giustiziato nel 309/922. ${ }^{1}$ I copisti di Baghdad, dopo la condanna di al-Hallāğ, dovettero giurare di non far circolare, né vendere, né comprare i suoi libri. ${ }^{2}$ D'altra parte, tutti gli scritti di Ğunayd sono lettere inviate ad altri sufi, la cui diffusione doveva essere ristretta a un circolo di iniziati; nemmeno per lettera, tuttavia, Ğunayd riteneva ammissibile uno stile troppo esplicito. ${ }^{3}$

Dato che il libro è un oggetto destinato a circolare, che "può cadere in mano a chiunque, chi ne è degno come chi non ne è degno', ${ }^{4}$ la conservazione del segreto esige in linea di principio una comunicazione esclusivamente orale. Un discorso esoterico ma scritto è di per sé un paradosso, perché vi si uniscono la segretezza legata all'oralità e la pubblicità legata alla scrittura. Tutta la letteratura sufi si è misurata con questo paradosso, comune ad altre tradizioni mistiche e filosofiche e particolarmente importante nella filosofia arabo-islamica. ${ }^{5}$ D'altra parte, la registrazione scritta degli insegnamenti dei grandi maestri del passato nei manuali composti fra IV/X e V/XI secolo è indispensabile per affermare il sufismo come madhab, cioè come una disciplina religiosa

1 A.T. Karamustafa, Sufism, 25.

2 Z. Szombathy, 'Freedom of Expression', 18; cfr. anche L. Massignon, Passion, 1: 676-8.

3 A.T. Karamustafa, Sufism, 18. Anche i cabalisti più contrari alla diffusione del segreto scrivono lettere: cfr. M. Idel, Kabbalah, 22.

${ }_{4}$ Al-Ša ${ }^{c}$ rānī, Durar al-gawwāș, 4 (wa-l-kitāb yaqa ${ }^{c} u$ fì yad ahlihi wa-gayr ahlihi).

5 Cfr. L. Strauss, Persecution and the Art of Writing; R. Brague, 'Athens, Jerusalem, Mecca'. Per una critica dell'interpretazione dell'esoterismo filosofico in Leo Strauss, cfr. M. Halbertal, Concealment and Revelation, 67, 136, 162. 
equiparabile alle discipline religiose tradizionali. ${ }^{6}$ Come le scuole di diritto, il sufismo costituisce una 'comunità testuale', ${ }^{7}$ identificata da un corpus di testi di base, attribuiti al fondatore eponimo o considerati come la registrazione scritta dei suoi detti, che costituiscono una letteratura specializzata la cui trasmissione e interpretazione deve essere controllata dai maestri.

I manuali sufi mantengono uno stretto legame con l'oralità sia per la forma che per la tecnica di scrittura. Per la forma perché, strutturati principalmente come raccolte di detti e aneddoti, adottano uno stile letterario che riproduce la parola detta, conformemente al modello della trasmissione del hadīt, ma anche della letteratura monastica tardoantica. ${ }^{8}$ Per la tecnica di scrittura, perché il linguaggio dei manuali, caratterizzato dalla natura specializzata del lessico tecnico (iștilāh) e dall'oscurità dell'allusione (išāara), presume la mediazione di un commento orale da parte di un maestro vivente capace di leggere fra le righe. ${ }^{9}$ Questo non ha impedito che i manuali servissero sin dal periodo classico come guida alla purificazione dell'anima inferiore in sostituzione di un maestro. ${ }^{10}$ L'uso dei manuali come guide alla fase preliminare del percorso spirituale, divenuto sempre più comune nei secoli successivi, non è però troppo problematico, perché la disciplina dell'anima non è una dottrina segreta ma un insegnamento pratico che si ispira spesso direttamente ai modelli stabiliti nella sunna.

Anche al-Ġazâlī (m. 505/1111), come lui stesso racconta nella sua autobiografia, avrebbe avuto la sua prima iniziazione al sufismo

6 Cfr. M. Malamud, 'Sufi organizations', 429-30. Per una descrizione sintetica del contesto storico in cui sono nati questi manuali si veda A.T. Karamustafa, Sufism, 83-113.

7 Su questa nozione, si veda B. Stock, Listening for the Text.

8 Sugli apophthegmata patrum come paradigma di 'oralità fittizia' nella letteratura cristiana si veda K.S. Frank, 'Fiktive Mündlichkeit'. Sulla possibilità che questa letteratura monastica abbia offerto un modello agli autori sufi anche attraverso canali di trasmissione scritta, si veda S. Chialà, 'Les mystiques musulmans'. Questa relazione avrebbe in seguito favorito l'imitazione dell'Ihy $\bar{a}^{\text {}}$ di al-Ġazālī nella letteratura religiosa siriaca del XIII secolo: vedi Ibid., 366-7.

9 Si veda C.W. Ernst, 'Mystical Language', 192-4; S.H. Nasr, 'Oral Transmission and the Book'. Per paralleli nella filosofia e nella mistica ebraica cfr. R. Brague, 'Athens, Jerusalem, Mecca', 243-4; E. Wolfson, 'Beyond the Spoken Word', 193.

10 Come nel caso di al-Hakīm al-Tirmid̄i (m. tra il 295/905 e il 300/910 ca.): si veda B. Radtke e J. O'Kane, The Concept of Sainthood, 1-2, 17. 
attraverso la lettura di tali libri. ${ }^{11}$ Il suo Ihy $\bar{a}^{\jmath}$ culüm al-dīn, uno dei più grandi 'best-seller' del medioevo islamico, si differenzia dai manuali che lo hanno preceduto perché, destinato a un pubblico più ampio, ha avuto un ruolo fondamentale nel promuovere il sufismo come 'letteratura' 12 La novità di al-Ġazālī non sta nella presunta riconciliazione del sufismo con l'ortodossia, che risale a un periodo anteriore, ma nel progetto di presentare il sufismo come parte integrante della 'cultura' degli 'ulama $\bar{a}^{\text {, }}$, promuovendo il sufismo più come $a d a b$ che come madhab. L'Ihy $\bar{a}^{\prime}$, proponendosi di introdurre gli ambienti scolastici alla pietà sufi, era espressamente rivolto a un pubblico di letterati non-iniziati, e destinato a circolare indipendentemente dall'insegnamento orale. Al termine dell'introduzione generale dell'opera, al-Ġazālī afferma di avere disposto la materia in modo simile ai trattati di diritto per invogliare alla lettura $\left(m u t a \bar{a} l a^{c} a\right)$ del libro i lettori privi di familiarità con i testi sufi, allo stesso modo in cui certi autori di trattati medici avevano scelto una veste grafica che imitava le tavole e i diagrammi dei testi astronomici. ${ }^{13}$ Non solo il termine mutălaca rinvia specificamente alla lettura visiva e silenziosa, distinta dalla qirā' $a$, che designa ugualmente la lettura ad alta voce, ma il paragone scelto da al-Ġazālī evoca un manufatto librario destinato allo sguardo.

Nell'atto di pubblicare il libro, al-Ġazālī si premura di chiarire preliminarmente che la sua trattazione è limitata all'unico aspetto della conoscenza sufi che può essere legittimamente comunicato, vale a dire la sua dimensione etica, o 'scienza dell'azione' ('ilm al-mu'ämala), contrapposta alla dimensione teorica, o 'scienza dello svelamento' ( ${ }^{c} \mathrm{ilm}$ al-mukāšafa). In linea con una convenzione sufi ben stabilita, al-Ġazālī dichiara infatti che la seconda non può essere scritta nei libri, ma se ne può parlare solo a chi ne è degno (ahluhu), attraverso l'insegnamento orale (mudāakara) o 'al modo dei segreti' (bi-tarīq al-asrār). ${ }^{14}$ Questa

11 Al-Ġazālī, Munqiẹ, 100-1.

12 Sulla valorizzazione della scrittura nell' 'lhy $\bar{a}^{\supset}$ come strumento di conoscenza almeno in parte indipendente dalla tradizione orale, vedi E. Moosa, Ghazā $\bar{l}$, soprattutto 93-117. Moosa interpreta l'Ihya $\bar{a}^{\supset}$ come la scoperta da parte di alĠazālī di una scrittura libera dall'ideologia dell'oralità e dall'autoritarismo che questa comporta. Anche se questa chiave di lettura decostruzionista è deliberatamente anacronistica, l'analisi del rapporto fra oralità e scrittura nell'opera di al-Ġazālī ha un indubbio interesse storico-letterario.

13 Al-Ġazālī, Ihyyāo , 1: 4-5.

14 Ibid., 19. Questo passo è tradotto e commentato in T.J. Gianotti, AlGhazāll's Unspeakable Doctrine, 52-6. Si veda anche A. Gil'adi, 'On the Origin of Two Key-Terms'. 
'comunicazione segreta' va intesa probabilmente come una comunicazione scritta ma chiusa; al-Ġazāli infatti spiega altrove che i veri ' ${ }^{\prime}$ ulam $\bar{a}^{\supset}$, come 'eredi dei profeti', devono imitare il riserbo di questi, che hanno trasmesso le conoscenze nascoste in una forma indiretta $\mathrm{e}$ allusiva, decifrabile solo dai pochi a cui l'accenno basta. ${ }^{15}$

Malgrado queste dichiarazioni programmatiche, l'Ihyya $\bar{a}^{\supset}$ è attraversato da continue allusioni alla 'scienza dello svelamento'. ${ }^{16}$ cAyn al-Quḍāt Hamadān̄i (m. 525/1131), un autore che fu condannato a morte per eresia con il pretesto che aveva mescolato gli insegnamenti dei sufi con quelli dei filosofi, si considerava 'discepolo dei libri di al-Ġazālī'. Nell'apologia che scrisse in carcere prima di essere giustiziato, ${ }^{\mathrm{C}} \mathrm{Ayn}$ alQuḍāt rivendica che le affermazioni condannate nei suoi scritti si ritrovano alla lettera nelle opere del suo autorevole predecessore. ${ }^{17}$

I libri di al-Ġazāīi, malgrado o forse a causa del loro successo, non hanno sempre avuto vita facile. In al-Andalus, oltre ad essere condannati al rogo dai fuqah $\bar{a}^{\supset}$ mālikiti del periodo almoravide ${ }^{18}$, sono stati criticati da Ibn Tufayl e da Ibn Rušd per avere trasgredito l'esoterismo politico proprio dei falāsifa. Ibn Rušd dichiara senz'altro che i libri di al-Ġazālī andrebbero proibiti agli incompetenti, perché, con la loro mescolanza dei livelli del discorso, sono colpevoli di una divulgazione dell'esegesi razionalista che li rende ben più dannosi dei libri dei filosofi. ${ }^{19}$ Fra VII/XIII e VIII/XIV secolo, del resto, le parti dei libri di al-Ġazālī consacrate allo 'svelamento' e al mondo invisibile suscitavano in Maghrib la diffidenza anche di alcuni sufi di tendenza tradizionalista (cfr. infra, par. 3).

Ciò nonostante, l'Ihyy $\bar{a}^{\supset}$ resta essenzialmente, come nelle intenzioni del suo autore, un'enciclopedia della 'scienza pratica' del sufismo. Nell'ambito della 'scienza teorica', il suo corrispettivo sono le Futūhāt makkiyya di $\operatorname{Ibn}^{\mathrm{c}} \mathrm{Arabī}$ (m. 638/1240), un autore che ha in comune con il suo predecessore l'ambizione di offrire una sintesi universale con il

15 Cfr. T.J. Gianotti, Al-Ghazāl̄’’s Unspeakable Doctrine, 50-1, 55-6.

16 Ibid., pp. 57-61.

17 F. Griffel, al-Ghazālī's Philosophical Theology, 81-7; si veda anche O.

Safi, The Politics of Knowledge, 162, 172-5.

$18 \mathrm{Si}$ veda M. Fierro, 'Opposition to Sufism in al-Andalus', 186, 191-5; F. Griffel, Apostasie, 365, 378; Idem, al-Ghazālī's Philosophical Theology, 80-1; M. Cook, Commanding Right, 455-6.

19 Averroè, Il trattato decisivo, 90. Cfr. anche D. Mallet, 'Les livres de Hayy'; R. Brague, 'Athens, Jerusalem, Mecca', 247; F. Griffel, Apostasie, 412 e 415. 
compito di infondere un nuovo spirito nella cultura religiosa del suo tempo. ${ }^{20}$

Ibn ${ }^{\mathrm{c}}$ Arabī condivide con al-Ġazālī anche un'ambizione divulgatrice. Che le sue idee mistiche, attraverso un canale comunicativo come la poesia, potessero raggiungere anche i letterati contemporanei, colpendoli per motivi estetici oltre che spirituali, è attestato dalla più antica notizia biografica su di lui, conservata nella antologia poetica di Ibn al-Ša ${ }^{c c} \bar{a} r$ alMawșilī (m. 654/1256). Al termine della biografia, prima delle poesie, si trova un elogio dello stile dell'autore, il cui 'bel discorso sulla realtà essenziale' (kalām hasan fì l-ḩaqīqa), prodotto di una diretta ispirazione, 'confonde le menti quando viene ascoltato e trascina i cuori quando è recitato'. ${ }^{21}$ Il fatto che il testo sufi abbia valore in se stesso per il suo carattere poetico non è una novità, visto che nelle letterature islamiche il confine fra poesia profana e poesia mistica è incerto. Nel caso di Ibn ${ }^{\mathrm{c}}$ Arabī, tuttavia, l'autonomia poetica del testo si estende anche alla prosa teorica, che trasforma creativamente lo stile descrittivo e prescrittivo dei manuali tradizionali facendone sorgere significati inediti e paradossali. ${ }^{22}$

La divulgazione, non necessariamente sinonimo di facilità, è in primo luogo legata a una rivendicazione di autorità. Nell'introduzione ai Fuṣuss al-hikam, Ibn ${ }^{\mathrm{c}}$ Arabī racconta che questo libro gli è stato trasmesso dal Profeta in una visione con l'ordine di divulgarlo: il libro del santo può essere legittimamente 'pubblicato' perché si colloca nel quadro di una storia sacra, come un prolungamento del messaggio profetico di cui condivide non la dimensione normativa, ma il fatto di trasmettere una conoscenza utile alla salvezza. Sui Fușuss al-hikam, più facilmente accessibili delle Futūḥăt, si sono concentrate le accuse contro Ibn ${ }^{\mathrm{c}} \mathrm{Arab} \overline{\mathrm{i}}$ nel 'processo postumo' che segna la storia religiosa dell'Islam premoderno a partire dal VIII/XIV secolo. Gli avversari hanno a più riprese raccomandato di distruggere i suoi libri, anche se tali drastiche misure sono state applicate solo occasionalmente e hanno avuto un successo limitato. $^{23}$

20 Sul parallelo fra al-Ġazālī e Ibn ${ }^{\mathrm{c}}$ Arabī e le affinità fra i loro progetti di 'rinnovamento': cfr. S. al-Hakīm, Ibn 'Arabī, 35-6; M. Mansiyya, 'al-Iğtihād', 125, 142-3; F. Rosenthal, 'Ibn 'Arabī between 'Philosophy' and 'Mysticism', 35, 34-5; J.W. Morris, 'Ibn 'Arabi’s 'Esotericism', 39; G.T. Elmore, Islamic Sainthood, 3, 10, 189-90.

21 G.T. Elmore, 'New Evidence', 60 e 69.

22 Si veda Chodkiewicz, 'Mi' rāj al-kalima'.

23 M. Chodkiewicz, 'Le procès posthume'; A. Knysh, Ibn 'Arabi, 124, 126, 127, 253, 261, 265; F. Rosenthal, 'Of Making Many Books', 39. 
La cautela—o l'aperta ostilità-nei confronti dei libri di Ibn ${ }^{\mathrm{c}}$ Arabī è dovuta anche al fatto che i commentatori di Ibn ${ }^{\mathrm{c}} \mathrm{Arab} \overline{\mathrm{i}}$, a partire dalla seconda metà del VII/XIII secolo, hanno creato sulla base delle sue opere una scuola mistico-filosofica che è stata uno dei principali canali di riabilitazione della filosofia soprattutto di matrice avicenniana nel tardo medioevo. In questo ambito si è costituita una nuova biblioteca di 'libri sulla haqĩqa' che rappresentano un genere a sé stante nella letteratura sufi. ${ }^{\mathrm{C}} \mathrm{Abd}$ al-Karīm al-Ğîlī, uno dei più originali rappresentanti della scuola di Ibn ${ }^{\mathrm{c}} \mathrm{Arab} \overline{\mathrm{l}}$, in un testo importante su cui ritorneremo nel terzo paragrafo, definisce i 'libri sulla haqīqa' come quelli che si occupano espressamente dell' 'essere' (wuğūd), fondando una 'gnosi salvifica' ( ${ }^{c}$ irfän) che può essere coltivata attraverso lo studio individuale anche indipendentemente dal percorso di purificazione interiore ${ }^{24}$. ${ }^{\mathrm{c}} \mathrm{Abd}$ alRazzāq al-Qāšānī (m. 730/1329), noto commentatore dei Fușuṣs, aveva scritto qualche decennio prima un dizionario dei termini tecnici del sufismo pensato per questo stesso tipo di lettori autodidatti, e più specificamente per intellettuali appartenenti alla tradizione filosofica avicenniana, non sufi anche se con inclinazioni per la mistica; che il dizionario di al-Qāšānī sia concepito come un ausilio alla lettura solitaria è indicato anche dalla disposizione dei lemmi in ordine alfabetico, un altro punto per il quale si discosta dai lessici contenuti nei manuali classici del sufismo..$^{25}$

L'importanza dell'opera di Ibn ${ }^{c}$ Arabī nella storia del sufismo è paragonabile a quella dello Zohar nella storia della mistica ebraica, a prescindere dalle affinità di contenuto e di stile, per il modo di trasmissione. La comparsa dello Zohar nella Spagna settentrionale della fine del VII/XIII secolo rappresenta infatti il punto di arrivo dello sviluppo di un corpus letterario svincolato dalla tradizione orale, che è stato considerato come il segno della transizione da una cultura orale a una cultura scritta. ${ }^{26}$ Anche se i cabalisti continuano ad aderire a un codice esoterico che impedisce la completa esposizione scritta di argomenti teorici o pratici particolarmente delicati, ${ }^{27}$ l'esistenza di un corpus letterario indipendente si presta allo studio individuale e apre la strada all'appropriazione della qabbalah da parte di filosofi non cabalisti, che la interpretano liberamente come una tradizione speculativa da

24 Al-Ǧ̄ilīi, Marātib, 7-12.

25 C.W. Ernst, 'Mystical Language', 183 e 186-7.

26 Si veda M. Halbertal, 'From Oral Tradition'; idem, Concealment and Revelation, 92-104; E. Wolfson, 'Beyond the Spoken Word', 177.

27 Vedi ibid., e M. Idel, Kabbalah, 20-2. 
affiancare al sapere filosofico rigettato in linea di principio dalla mistica ebraica tradizionale. Questo fenomeno, che assume particolare rilevanza nell'ebraismo italiano, diventerà uno dei più importanti stimoli del pensiero rinascimentale. ${ }^{28}$

Un altro notevole parallelismo fra la mistica ebraica e il sufismo del VII/XIII secolo e oltre è il nesso fra rivelazione del segreto e messianismo, nel contesto di una concezione della storia vista come il dispiegarsi di una sempre maggiore chiarezza nella conoscenza delle realtà metafisiche e nella loro 'pubblicazione'. Questa visione dinamica della storia implica che la disciplina del segreto ha un carattere solo provvisorio, diventando meno rigorosa man mano che ci si avvicina all'era messianica. ${ }^{29}$

Sia nell'ebraismo che nell'islam, questi sviluppi nelle forme comunicative e nelle idee a cui sono collegate hanno incontrato resistenze all'interno delle rispettive tradizioni mistiche. In entrambi i casi infatti la trasformazione della tradizione esoterica in 'letteratura' e la sua trascrizione in libri che possono finire in mano a chiunque mettono in pericolo la nozione stessa di 'tradizione', che è alla base tanto della qabbalah (che significa appunto 'ricezione' di qualcosa che è trasmesso oralmente), quanto del sufismo (che si ricollega al Profeta attraverso la 'catena iniziatica' [silsila], corrispettivo sufi dell'isnād). ${ }^{30}$

In ambito islamico, i sufi 'moderati', fra i due estremi dei fautori della distruzione dei libri di Ibn ${ }^{\mathrm{c}}$ Arabī e della loro divulgazione, sostengono che questi libri non vanno messi nelle mani di chiunque e ne sconsigliano la lettura ai novizi. Per questo motivo, l'influenza di Ibn ${ }^{\mathrm{c}}$ Arabī sulle confraternite, per quanto importante, è rimasta spesso implicita. ${ }^{31}$

L'esistenza di libri specializzati non pone di per sé in questione la necessità del maestro né nella tradizione sufi né nelle altre scienze religiose. Il sufismo, come è noto, insiste sin dal periodo classico sulla

28 Si veda B. Ogren, Renaissance and Rebirth, 27-30 e 37.

29 Per alcune testimonianze in tal senso nell'ebraismo del XIII secolo si veda R. Brague, 'Athens, Jerusalem, Mecca', 249; E. Wolfson, 'Beyond the Spoken Word', 178-9; M. Halbertal, Concealment and Revelation, 33, 105-13. Sullo sviluppo di questi concetti nel sufismo, e in particolare sulla relazione fra il 'discorso chiaro' (bayān) del santo perfetto e l'attesa di un 'rinnovamento' in Ibn 'Arabī e nei suoi epigoni, si veda S. Pagani, Il rinnovamento, 53-66 e 95-140.

30 Sulle obiezioni contro il libro nella mistica ebraica si veda M. Idel, Kabbalah, 19-20; E. Wolfson, 'Beyond the Spoken Word', 175-6; M. Halbertal, 'From Oral Tradition'; idem, Concealment and Revelation, 71-2, 136.

31 M. Chodkiewicz, Océan, 17-37; idem, 'Le procès posthume', 116. 
necessità del maestro: secondo un detto celebre attribuito a al-Bisțāmī (m. 261/874 o 264/877), 'Satana è l'imām di chi non ha maestro'.32 Ma la relazione maestro-discepolo si è evoluta nel tempo: la progressiva istituzionalizzazione del sufismo ha portato infatti a una formalizzazione di questa relazione, così come in genere della condotta dei discepoli e dei loro rapporti reciproci, fino alla fissazione di vere e proprie regole fra VI/XII e VII/XIII secolo. Nella codificazione del rapporto maestrodiscepolo ha un posto di primo piano il dovere di ubbidienza assoluta, base del principio di autorità nelle confraternite (țuruq) che si costituiscono a partire dal VI/XII secolo. ${ }^{33}$

Una delle più antiche regole sufi conservate prescrive di 'legare il cuore al maestro': il discepolo deve imprimere nel proprio cuore l'immagine del maestro, in modo che questo sia sempre presente davanti al suo occhio interiore. ${ }^{34}$ In questo forte legame personale, la parola del maestro ha una funzione essenziale, non tanto per l'insegnamento che trasmette, quanto per il suo potere di trasformare interiormente l'allievo. ${ }^{35}$ La parola del maestro si iscrive nel cuore dell'allievo come la parola rivelata nel cuore del Profeta ${ }^{36}$. Al-Šādilī, quando gli venne chiesto perché non avesse scritto libri, rispose: 'I miei libri sono i miei allievi' (kutubī aṣhāāì). ${ }^{37}$

Questa pedagogia spirituale, in cui tanta parte ha la presenza fisica del maestro, con la gestualità extra-verbale legata a questa presenza, caratterizza il 'maestro educatore' (šayh murabbī), cioè colui che ha il

32 Al-Qušayrī, Sendschreiben, 538. Cfr. A.T. Karamustafa, Sufism, 117; M. Malamud, 'Sufi organizations', 440 nota 33; L. Silvers-Alario, 'The Teaching Relationship'.

33 Su questo processo si veda F. Meier, 'Khurāsān'; idem, 'Qusăyrī’s Tartīb'. M. Malamud, 'Sufi organizations', riesamina in parte le stesse fonti aggiungendo interessanti osservazioni sul parallelismo fra i sistemi di trasmissione del sapere nel sufismo e nelle scuole legali. Sul rapporto tra la fissazione di 'regole' scritte e la nascita delle confraternite si veda B. Radtke, 'The eight rules'.

34 Ibid., 496.

35 Cfr. le descrizioni della dettatura della formula di invocazione (talqīn aldikr): E. Ohlander, Sufism, 224-5; M. Chodkiewicz, 'Note complémentaire', 49. Sul talqin anche A.T. Karamustafa, Sufism, 135, n. 16. L'attribuzione di un potere creativo alla parola dello šayh sembra peraltro coincidere con l'emergere delle turuq nel XII secolo: cfr. S. Sviri, 'Kun - the Existence-bestowing Word', 37-8.

36 Cfr. la descrizione dell'inizio della rivelazione in Ibn Ishāa, cit. in Piemontese, 'Sistema e strumenti dell'Islam', 286. Sul tema della 'scrittura del cuore' nell'Islam cfr. anche A. Neuwirth, Der Koran als Text, 163-8.

37 Ibn ${ }^{\mathrm{c}}$ Ațā̄o Allāh, Lațā̄if, 50. 
compito di 'allevare' l'aspirante, piuttosto che di 'istruirlo' trasmettendogli un sapere. Come vedremo nel terzo paragrafo, i due modelli educativi della 'pedagogia spirituale' (tarbiya) e dell' 'insegnamento dottrinale' ( $\operatorname{ta}^{c} \mathrm{l} \mathrm{l} m$ ) possono entrare in conflitto, anche se idealmente sono complementari, come dovrebbero esserlo teoria e prassi, speculazione e rituale, haqīqa e țariqa.

La fioritura, nello stesso periodo della nascita delle confraternite, di 'libri sulla haqĩ $a^{\prime}$ ' che pretendono di costituire un accesso privilegiato a una conoscenza salvifica descritta come l'essenza dell'eredità profetica, ${ }^{38}$ è una sfida potenziale per gli šayh delle țuruq, custodi di un'altra variante dell'eredità profetica, la facoltà di istituire sunan (le regole e i rituali della tarīqa) e di essere quindi un modello per l'azione, oggetto di imitazione al pari del Profeta. ${ }^{39}$

Oltre che i modelli educativi, il conflitto può riguardare anche i contenuti, come indica il fatto che ad alcuni grandi maestri di confraternite è attribuita la distruzione di testi mistici e filosofici. Nel caso di ${ }^{\mathrm{c}} \mathrm{Abd}$ al-Qādir al-Ğ̄ilānī (m. 561/1166), fondatore eponimo della Qādiriyya, la distruzione si inserisce in un racconto agiografico, ed è presentata come un miracolo:

Una volta, quand'ero giovane, mi presentai al cospetto dello šayh ${ }^{\mathrm{c}} \mathrm{Abd}$ alQādir-che Dio sia soddisfatto di lui! — con una numerosa compagnia. Avevo con me un libro che trattava di filosofia e di scienze spirituali ( ${ }^{c} u l u \bar{m}$ al-rūhāniyyāt). Appena fui entrato alla sua presenza, lo šayh mi parlò, rivolgendosi direttamente a me, non al resto del gruppo. Prima ancora di avere esaminato il libro, o di avermi interrogato sul suo contenuto, mi disse: 'Quel tuo libro è un cattivo compagno. Faresti meglio a cancellarlo con l'acqua!' Pensai allora di allontanarmi, chiudere il libro da qualche parte, e astenermi in seguito dal portarlo con me, per timore di offendere lo šayh. La mia anima inferiore non poteva accettare l'idea di cancellarlo con l'acqua, perché gli ero molto affezionato e alcune delle sue teorie e dei suoi principi avevano risvegliato la mia curiosità intellettuale. Mentre stavo per alzarmi ed andarmene, con l'intento di mettere in atto il mio proposito, lo šayh mi lanciò una tale occhiata, che fui incapace di alzarmi. Mi sentivo come paralizzato. Ma lui mi disse: 'Dammi quel tuo libro!' Allora lo aprii, e-guarda un po'!-vidi che non conteneva altro che fogli bianchi, senza che vi fosse scritta una sola lettera. Quindi lo diedi allo šay h , che lo sfogliò e poi disse: 'Questo è il Libro delle eccelse virtù del Corano di Muhammad Ibn al-Durays' Quando me lo restituì, vidi che era proprio quel libro lì, scritto in una magnifica calligrafia. Quindi lo šayh mi disse: 'Sei pronto a

38 Così in chiara sintesi al-Ğīlī nel prologo dei Marātib, 7-12.

39 Cfr. D. Gril, 'Le saint fondateur'. 
pentirti per aver detto con la lingua qualcosa che non è nel tuo cuore?' 'Sì, maestro', risposi. Infine mi ordinò di alzarmi. Ubbidii, ed ecco che avevo dimenticato tutto della filosofia e dei principi di spiritualità. Erano stati completamente cancellati dalla mia interiorità, come se non me ne fossi mai occupato. ${ }^{40}$

In questo racconto, dove l'ubbidienza dovuta allo šayh si contrappone all'infatuazione per la filosofia e le 'scienze spirituali', il libro proscritto resta anonimo. Più tardi, il grande sufi kubraw̄̄ ${ }^{\mathrm{c}} \mathrm{Ala}{ }^{\circ}$ al-Dawla alSimnānī (m. 736/1336), noto per le sue polemiche contro la scuola di Ibn

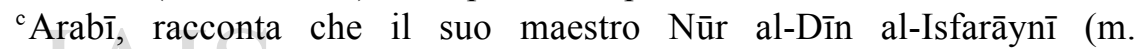
717/1317) 'soleva proibire la lettura degli scritti di Ibn ${ }^{\mathrm{c}}$ Arabī, ed era così severo al riguardo che, avendo sentito che [...] due dei suoi allievi

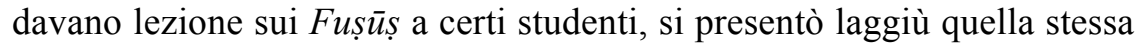
notte, strappò loro di mano il manoscritto, lo stracciò e ingiunse il divieto assoluto di leggerlo'. ${ }^{41}$

Uno dei casi meglio documentati di distruzione di libri da parte di un maestro sufi è quello di ${ }^{\mathrm{c}}$ Umar al-Suhrawardī (m. 632/1234), come ${ }^{\mathrm{c}} \mathrm{Abd}$ al-Qādir fondatore eponimo di una țarīqa. Autore di libri sulla $m u^{c} \bar{a} m a l a$ considerati 'buoni' anche dai più severi censori del sufismo, alSuhrawardī ha combattuto la tradizione filosofica ellenizzante non solo per scritto ma anche attraverso la distruzione materiale. Egli stesso si è infatti vantato di avere cancellato con l'acqua lo Šif $\bar{a}^{\jmath}$ di Avicenna, nel contesto della sua collaborazione con il califfo ${ }^{c}$ abbaside al-Nāṣir, la cui politica religiosa portò a roghi di biblioteche che si sospettavano contenere letteratura filosofica e alla cancellazione di singoli libri particolarmente 'pericolosi'. ${ }^{42}$

Questi tre casi presentano una notevole differenza rispetto alle distruzioni di libri attribuite ad asceti più antichi, come Sufyān al-Tawrī (m. 161/778), Dāwūd al-Ṭā̄̄̄ (m. 165/781-2) e Abū Sulaymān al-Dārānī (m. 205/820 o 215/830), citati da al-Tawhīīi (m. 411/1023) come precedenti nell'epistola in cui giustifica la scelta di bruciare le sue stesse opere. Per questi personaggi infatti la distruzione dei libri coincide con

40 al-Tādifî, Necklaces, parte 8. Lo stesso testo è citato in A. Rippin, Muslims, 146.

41 H. Landolt, 'Der Briefwechsel', 75.

42 A. Hartmann, an-Nāșir, 255-62; E. Ohlander, Sufism, 291-300; cfr. anche F. Griffel, Apostasie, 353. Tra le vittime più illustri di questa persecuzione ci fu un nipote di c Abd al-Qādir al-Ǧ̄ilānī: Rukn al-Dīn al-Ǧīlī (m. 611/1214), la cui biblioteca di testi scientifici e filosofici fu bruciata nel 588/1192-3: cfr. A. Hartmann, an-Nāṣir, 256-60; L. Richter-Bernburg, 'Ibn al-Māristānīya', 274. 
l'inizio della vita ascetica, ovvero con una rinuncia al mondo, le cui vanità includono un sapere inutile ai fini della salvezza. ${ }^{43}$ In questo caso, la distruzione dei libri è il segno di un atteggiamento anti-scolastico ben compendiato nel detto attribuito a al-Bisțāmī in cui il mistico contrappone da parola viva della conoscenza spirituale alla lettera morta degli ${ }^{c}$ ulam $\bar{a}^{\text {}}$ : 'Avete preso la vostra scienza morto da morto, mentre noi abbiamo preso la nostra dal Vivo che non muore'. ${ }^{44}$ Al contrario, la distruzione di libri da parte di autorevoli maestri di țruq è una deliberata opera di censura di tradizioni sapienziali e spirituali concorrenti all'interno di una cultura sufi che nel frattempo si è uniformata in buona parte alle modalità scolastiche della trasmissione del sapere. ${ }^{\mathrm{c}} \mathrm{Abd}$ alQādir, nel suo 'miracolo', sostituisce un libro 'utile' a un libro 'pericoloso', ma non bandisce lo studio e la lettura in sé - anzi promuove lo studio di un classico delle scienze religiose tradizionali. ${ }^{\mathrm{c}}$ Umar alSuhrawardī, da parte sua, contribuisce a cancellare una tradizione filosofica a cui sostituisce i suoi stessi libri, portatori di una gnosi

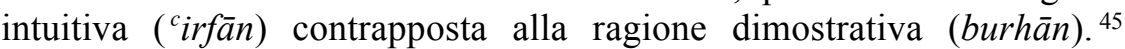
Inoltre, l'istituzionalizzazione del 'maestro educatore' (šayh al-tarbiya), alla quale al-Suhrawardī ha dato un contributo teorico decisivo, è perfettamente compatibile con lo studio. In effetti, l'educazione può anche farsi a distanza, attraverso il libro del maestro, e in questo caso l'iniziazione coincide con l'autorizzazione a trasmettere i suoi libri. ${ }^{46}$ Anche se i maestri possono esercitare la loro autorità come censori, le turuq alimentano un'ampia produzione manualistica, agiografica $\mathrm{e}$ devozionale che contribuisce alla diffusione del libro e della lettura.

\footnotetext{
43 al-Qāḍī, 'Scholars and Their Books', 627-8, 630-1, 638-9. Cfr. anche F. Rosenthal, 'Of Making Many Books', 39-43.

44 Cfr. Ibn 'Arabī, Futūhāt, 1:198, 254, 257, 280; 2: 252-3. Sulla contrapposizione fra conoscenza ispirata e conoscenza libresca in Ibn 'Arabī, cfr. F. Rosenthal, 'Ibn 'Arabī between 'Philosophy' and 'Mysticism', 32. Nell'autobiografia di al-Ša ${ }^{c}$ rānī, la rinuncia ai libri (che tuttavia non vengono distrutti, ma venduti, dando il ricavato in elemosina), rappresenta la prima tappa del suo discepolato con il maestro 'illetterato' cAlī al-Hawwāṣ. Ma questo doloroso distacco ('fu come se fossi stato spogliato della scienza' - hattā ka'annī sulibtu min al- ${ }^{c} i l m$ ) prelude alla trasformazione dell'allievo in uno scrittore originale, che può mettere per iscritto le proprie intuizioni 'senza avere più

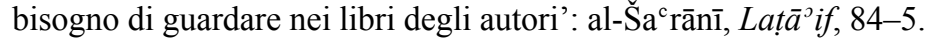

45 Si veda E. Ohlander, Sufism, 302.

46 Ibid., 141.
} 
Autodidattismo, tradizione e innovazione nelle scienze religiose tradizionali e nel sufismo

L'esigenza di controllare un sapere scritto in costante espansione è comune in questo periodo al sufismo e alle altre scienze religiose. In effetti, fra VII/XIII e VIII/XIV secolo, l'autodidattismo e la trasmissione testuale svincolata dalle forme tradizionali di verifica orale sembrano essersi intensificati anche nell'ambito della madrasa.

In Maghrib, nella seconda metà del VIII/XIV secolo, alcuni autori denunciano che fra gli studenti di Granada e di Fez si è diffusa la pratica di studiare individualmente i compendi di diritto, trascurando l'insegnamento orale dei maestri. ${ }^{47}$ Qualche decennio prima, nell'Egitto mamelucco, il giudice šāficita Ibn Ğamāca (m. 733/1333), nel suo libro sull'educazione nelle scienze religiose, mette in guardia dal prendersi come maestri coloro che hanno 'studiato i significati reconditi delle pagine (buțūn al-awrāq) ma non hanno frequentato un maestro esperto' un fenomeno che viene definito sprezzantemente tašy 'trasformare la pagina in maestro' ${ }^{48}$ In effetti, secondo Ibn Ğamă $\overline{\bar{a}}^{\mathrm{c}} \mathrm{a}$, 'la conoscenza non può essere tratta dai libri: questa è una delle più dannose cause di corruzione' (al- 'ilm la yu'hadu min al-kutub fa-innahu min aḍarr al-mafāsid $)^{49}$. Questo ovviamente non significa che uno studente non possa leggere da solo, ma che, per evitare errori, prima di memorizzare un testo, deve verificarne la correttezza con un maestro o con un ripetitore designato da questi. ${ }^{50}$ Inoltre, lo studente principiante deve affidarsi al maestro e non ai libri per l'interpretazione dei testi. ${ }^{51}$

In altri termini, la lettura solitaria dei principianti va regolata per garantire la corretta trasmissione e interpretazione dei testi, ma è ovviamente parte integrante dell'educazione. Ibn Ğamāc ${ }^{c} a$ dedica infatti un intero capitolo alle 'regole da osservare con i libri che sono lo strumento del sapere', 52 dove raccoglie varie raccomandazioni sul metodo da seguire nella lettura privata. La 'metodologia dello studio

47 Si veda P. Nwyia, Ibn ${ }^{c} A b b \bar{a} d$, xlvii-xlviii. Cfr. anche V. Cornell, Realm, $127-8$.

48 Ibn Ğamā̄a, Tadkira, p. 116. Su questa formula cfr. anche W.A. Graham, Beyond the Written Word, 104.

49 Ibn Ğamā $\bar{c}^{\mathrm{c}}$, Tadkira, 131. Su questi passi e altri esempi in proposito: J. Berkey, Transmission, 26; D. Ayalon, Reading Palestine, 111-12; E. Moosa, Ghazālī, 97-8.

50 Ibn Ğamā̄a, Tadkira, 131.

51 Ibid., 129-30.

52 Ibid., 143-51. Su questo capitolo dell'opera e la sua rielaborazione nel XVI sec., si veda F. Rosenthal, Technique, 7-18. 
individuale' ( $\bar{a} d \bar{a} b$ al-muțālaca) diventa oggetto di una trattazione specifica alla fine del XI/XVII secolo, da parte del famoso astronomo ottomano e sufi mawlawi Aḥmad Dede ibn Luṭfallāh Müneğğim Baši (m. 1113/1702), ${ }^{53} \mathrm{ma}$ in questo caso l'autore innova perché si propone deliberatamente di facilitare e incoraggiare l'apprendimento senza maestri. Nella sua opera infatti la muțăla $a$ è descritta come un esercizio intellettuale che consiste nell' "estrarre i significati delle espressioni linguistiche attraverso la lettura visiva e la riflessione', e si oppone per definizione al taqlìd, la ricezione di una conoscenza in base al solo principio di autorità, senza conoscerne la prova. ${ }^{54}$

Per quanto riguarda la trasmissione materiale del libro, nel corso del medioevo il principio del controllo orale si mostra sempre più come una fiction, il cui mantenimento è determinato in primo luogo da ragioni ideologiche, come osserva G. Vajda a proposito di forme di 'autorizzazione a trasmettere' che non comportano il diretto ascolto dei testi, come l'iğāza 'generale', o quella trasmessa per lettera, o quella accordata a bambini o a persone non ancora nate. ${ }^{55}$

In uno studio recente, Denis Gril ha mostrato che l'abitudine di collezionare e moltiplicare le iğāza $\bar{a} t$ ha un corrispettivo 'esoterico' nella creazione, a partire dal periodo ayyubide, di repertori di catene iniziatiche diffusi in un ambiente di ${ }^{\mathrm{c}} u \operatorname{lam} \bar{a}^{\supset}$ sempre più aperto al sufismo. Le catene iniziatiche registrate in questi repertori, costruite sul modello dell'isnād nel hadīt, sono trasmesse spesso sulla base di altri testi, cioè in modo puramente libresco, sebbene questo non sia esplicitato. Non sono dunque la testimonianza del perpetuarsi della tradizione vivente di un insegnamento da maestro a discepolo, ma servono piuttosto a stabilire un legame simbolico con i grandi maestri del passato, e, attraverso di loro, con il Profeta. Come osserva Denis Gril nella conclusione del suo studio, 'cette évolution se situe dans le cadre plus large d'une économie du savoir et du milieu qui le porte'. ${ }^{56}$

In effetti, un'evoluzione importante si è verificata nel VII/XIII secolo nelle scienze del hadīt, paradigma della centralità della trasmissione orale nel sapere religioso islamico. La trattatistica dell'epoca testimonia

53 Cfr. J.H. Kramers, 'Münedjdjim Bāshi,' $E I^{2}$.

54 Mawlawī, Fayḍ al-ḥaram, f. 3a (istihrā̄̆ al-ma ānī min al-ibārāt bi-

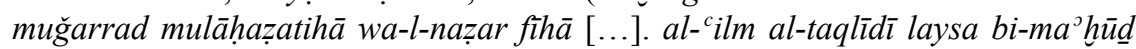
min al-dalīl fa-garaḍhu min al-muțālac $a$ an yuhaqqiqa dâlika al- ${ }^{c}$ ilm bi-ahdihi min al-dalīl).

55 Cfr. G. Vajda, 'Idjāza,' $E I^{2}$.

56 D. Gril, 'De la khirqa à la țarīqa', 80. 
la diminuita importanza dell'isnād come strumento di autenticazione delle tradizioni: una copia autenticata del testo è sufficiente garanzia di autenticità, e può essere copiata direttamente. In queste mutate condizioni, la trasmissione testuale è affiancata da forme 'ritualizzate' di trasmissione orale, mentre gli isnād si continuano a collezionare per interesse 'spirituale': particolarmente apprezzati da questo punto di vista sono quelli con il minor numero di garanti, perché accorciano la distanza fra il ricevente e il Profeta. ${ }^{57}$

La pratica della lettura privata, scontata nelle 'scienze straniere' e nell'adab, dove non a caso il libro è lodato anche per il suo silenzio, ${ }^{58}$ è scoraggiata nelle scienze religiose perché mette in pericolo la continuità della tradizione. Avere una biblioteca permette di viaggiare nel tempo, ma questa libertà di movimento elimina la mediazione delle autorità che controllano l'interpretazione dei testi. I grandi 'innovatori' sono quelli che viaggiano a ritroso nel tempo. Lo mostra bene, nel campo del diritto di questo periodo, il caso di due personalità per tanti versi opposte, ma unite dalla rivendicazione dell' iğtihă $d$, come Ibn ${ }^{\mathrm{C}}$ Arabī e Ibn Taymiyya (m. 728/1328).

Ibn 'Arabī scavalca l'autorità dei fuqah $\bar{a}^{\supset}$ mālikiti contemporanei rifacendosi direttamente a Ibn Ḥazm (m. 456/1064), esponente anticonformista del mad̆hab zāhirita. Secondo Ibn Hualdūn, questa scuola giuridica minoritaria era sopravvissuta solo attraverso i libri, e Ibn Hazm, come altri seguaci della scuola, avrebbe avuto il torto di apprenderne $\mathrm{i}$ principi studiando i testi senza passare attraverso la mediazione dei maestri. L'indipendenza di giudizio e la mancanza di rispetto per le autorità legate a questo metodo di studio individualistico avrebbero fatto incorrere Ibn Hazm nella disapprovazione, a tal punto che i suoi stessi libri in certe occasioni furono vietati e distrutti. ${ }^{59}$ Comunque sia, la

57 E. Dickinson, 'Ibn al-Ṣalāḥ'.

58 Si veda $\mathrm{A}$. Ghersetti, 'L'utilità della scrittura'. Sul valore del libro come strumento di perfezionamento nella letteratura filosofica, si veda D. Mallet, 'Les livres de Hayy', 4.

59 Ibn Haldūn, The Muqaddimah, 3: 6. Sulla tendenza a basarsi esclusivamente sui libri come caratteristica della scuola zāhirita si veda C. Melchert, The Formation, 189-90. È possibile in ogni caso che Ibn Haldūn insista sul fatto che la dottrina di Ibn Hazm fosse basata solo sui libri allo scopo di stigmatizzarla. Sembra infatti che Ibn Hazm abbia avuto almeno un maestro zāhirita: si veda C. Adang, 'The Spread of Z̄āhirism', 302. Si veda anche ibid., 303 , sulle circostanze che portarono alla distruzione dei libri di Ibn Ḥazm. In alAndalus, i rapidi cambiamenti di ortodossia portarono anche al rogo di libri mālikiti: si veda I. Goldziher, The Zāhirī̄s, 160. 
tentazione di seguire questa scuola senza maestri viventi riemergeva regolarmente, e il caso di Ibn ${ }^{\mathrm{C}}$ Arabī sembra confermarlo, dato che egli se ne ispira nella sua ermeneutica legale, anche se la sua effettiva adesione alla scuola è dibattuta.$^{60}$

Per quanto riguarda Ibn Taymiyya, la sua rottura del consensus è imputata dal suo avversario Taqī l-Dīn al-Subkī (m. 756/1355) al fatto che non avrebbe avuto un maestro: 'Il diavolo era con lui perché il diavolo sta con chi è solo'. ${ }^{61}$ Ibn Taymiyya stesso aveva peraltro criticato l'ubbidienza incondizionata degli adepti nei riguardi dei maestri sufi, dedicando uno scritto indipendente alla critica del celebre adagio sufi secondo il quale 'satana è il maestro di chi non ha maestro' ${ }^{62}$

La combinazione di lettura solitaria e rivendicazione dell'iğtihăd è ugualmente presente nella carriera di un ${ }^{c}$ ālim-sufi come Ğalāl al-Dīn alSuyūṭ̂̄ (m. 911/1505), forse l'autore più prolifico del periodo premoderno, che secondo uno dei suoi biografi era stato soprannominato 'figlio dei libri' (ibn al-kutub) perché era nato in una biblioteca. AlSuyūṭ̂̄ fu criticato molto violentemente da alcuni contemporanei perché aveva avuto scarsi rapporti diretti con i maestri e aveva ricevuto gran parte della sua istruzione solo attraverso i libri. A queste accuse si aggiungono quelle di plagio - come se l'accesso incontrollato ai testi predisponesse al furto e al saccheggio. ${ }^{63}$

Al-Suyūṭ̂̄ oltretutto pretendeva di ricevere direttamente dal Profeta informazioni sull'autenticità del hadīt. In una lettera, scrive di avere avuto fino a quel momento settantacinque incontri spirituali con il Profeta, e che tali incontri sono uno strumento indispensabile per la sua attività di tradizionista. ${ }^{64}$ Alla base di questa rivendicazione c'è con ogni probabilità la dottrina di Ibn 'Arabī secondo la quale lo 'svelamento' è un criterio valido per stabilire l'autenticità del hadīt. ${ }^{65}$ Eppure, l'idea di una ricezione diretta del hadi $\underline{t}$ dal Profeta si riscontra anche nella scienza del hadịt come viene codificata nel VII/XIII secolo. Come si è

60 Cfr. M. Chodkiewicz, Océan, 78; G.T. Elmore, Islamic Sainthood, 43.

61 C. Bori, Ibn Taymiyya, 166-8.

62 Ibid., 168. Più tardi, anche la dottrina di Ibn ${ }^{\mathrm{c}} \mathrm{Abd}$ al-Wahhāb, grande ammiratore di Ibn Taymiyya, sarebbe stata considerata dai detrattori il frutto di una immoderata lettura solitaria, non bilanciata dallo scambio orale con i detentori viventi della scienza: si veda M. Cook, 'On the Origins', 191.

63 Si veda E.M. Sartain, Jalāl al-Dīn al-Suyūțī, 1: 24 e 74-5.

64 La lettera è citata in al-Š̉a ${ }^{c}$ rānī, al-Mīzān al-kubrāa, 1: 35. Cfr. anche É. Geoffroy, Le soufisme, 100, n.70.

65 Ibn ${ }^{\mathrm{c}}$ Arabī, Futūhāt, 1: 150, 224-5; 2: 97, 254; 3: 13, 413. Cfr. anche M. Chodkiewicz, Sceau, 80 e 99. 
accennato, a quest'epoca si afferma la tendenza a collezionare hadīt con l'isnād più breve possibile, a cui si attribuiva un particolare valore 'spirituale' perché accorciava la distanza dal Profeta. Questo procedimento, come commenta E. Dickinson, "made time elastic and gave those unlucky enough to have been born late the opportunity to enjoy the spiritual superiority of earlier generations'; ${ }^{66}[\ldots]$ 'the general thrust was that one should avoid intermediaries. This argument was almost subversive, for the whole theoretical justification for hadith transmission rested on the principle that one must accept information from trustworthy intermediaries' ${ }^{67}$ Infatti, poiché il fine era quello di accorciare le distanze, si poteva arrivare a saltare del tutto gli intermediari, ricevendo il hadit in sogno direttamente dal Profeta: un privilegio rivendicato da autorevoli tradizionisti e giuristi di questo periodo e anche di epoche precedenti. ${ }^{68}$

In un trattato in cui sostiene, basandosi principalmente su al-Suyūțī, la validità dell'autorizzazione a trasmettere ricevuta in sogno, ${ }^{\mathrm{c}} \mathrm{Abd}$ alĠan̄i al-Nābulusī (m. 1143/1731) afferma che questo tipo di autorizzazione equivale a un' 'autorizzazione generale' (iğ $\left.\bar{a} z a{ }^{\prime a} \bar{a} m m a\right)$ : anche quest'ultima infatti è svincolata da una trasmissione orale, in quanto l'autorizzato non ha ascoltato il testo dalla viva voce del trasmettitore. Il sogno, dunque, è un sostituto fittizio della trasmissione orale, allo stesso titolo dell'iğāza che non comporta un ascolto effettivo. Entrambe le modalità hanno soltanto una funzione di baraka, per cui la validità del testo ricevuto in sogno o per trasmissione indiretta dev'essere verificata controllandone la corrispondenza con il testo trasmesso secondo le regole. ${ }^{69}$

La 'visione' di un autore del passato non è necessariamente il segno di un'esperienza mistica, ma l'espressione simbolica della contemporaneità con l'autore che si verifica nel rapporto diretto e personale fra il lettore e il testo. ${ }^{70} \mathrm{~L}$ 'aspirazione al 'faccia a faccia' con l'autore del passato, o con la fonte di autorità per eccellenza - il Profeta, o il Corano -, è in conflitto con il principio della mediazione attraverso una catena affidabile di trasmettitori e di interpreti. La tensione fra

66 E. Dickinson, 'Ibn al-Ṣalāḥ’, 504.

67 Ibid., 496.

68 Ibid., 494, 503-4. Si veda anche L. Kinberg, 'Dreams', 79-99.

69 Al-Nābulusī, Rawọ al-anām. Al-Nābulusī racconta altrove di avere lui stesso ricevuto una iğāza in sogno da al-Hुaḍir: cfr. B.R. von Schlegell, Sufism, 201.

$70 \mathrm{Si}$ vedano a proposito del commento medievale le belle pagine di E. Coccia, La trasparenza delle immagini, 3-19. 
queste due forze è una costante della cultura islamica, che, come mostra la moda dell'isnād abbreviato nella scienza del hadīt, è presente nel cuore stesso del sapere religioso. Questa tensione caratterizza anche il sufismo, proprio in quanto è parte di un contesto culturale al tempo stesso orale e scritto. Nel sufismo, le 'innovazioni' si presentano come la rottura della trasmissione orizzontale del sapere veicolata dalla catena iniziatica della tarīqa e il ritorno a un'autorità anteriore, che può essere un santo del passato, o il Profeta, o Dio stesso. L'iniziazione attraverso la contemplazione della 'forma spirituale' (rūhāniyya) di un santo assente o defunto è definita uwaysī, sul modello di Uways al-Qaranī, un personaggio che secondo la leggenda sarebbe vissuto in Yemen all'epoca del Profeta e avrebbe comunicato telepaticamente con lui. ${ }^{71}$ Le iniziazioni di tipo uways $\bar{\imath}$ servivano spesso a giustificare trasformazioni significative della tradizione, o a segnare la nascita di nuovi rami di una confraternita. ${ }^{72}$

Il maestro che istruisce a distanza di spazio o di tempo spesso è l'autore di un libro, o il libro stesso. Per esempio, il sufi persiano Kāzarunī (m. 426/1033), nel periodo in cui cercava invano un maestro, sognò che qualcuno venne da lui con un cammello carico di libri e gli disse: 'Questi sono i libri dello šayh Ibn Hafiff (m. 371/982), che li ha mandati apposta per te con questo cammello'. ${ }^{73}$ Un sufi šādilita magrebino della fine del VIII/XIV secolo affermava di essere allievo di Ibn ${ }^{\mathrm{c}}$ Ațā̄ ${ }^{\circ}$ Allāh al-Iskandarī (m. 709/1309), anche se questo era già morto da tempo, perché aveva letto le sue Hikam e il commento che ne aveva fatto Ibn ${ }^{\mathrm{c}}$ Abbād di Ronda (m. 792/1390). ${ }^{74}$

Il fenomeno dell'iniziazione attraverso la 'forma spirituale' di un autore è particolarmente frequente nella scuola di Ibn ${ }^{\mathrm{c}} \mathrm{Arab} \overline{\mathrm{i}}$, dove lo studio dei libri del maestro era considerato fondamentale. Hasan al-

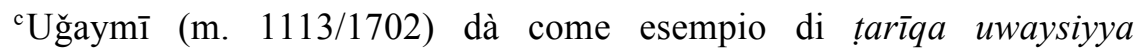
l'iniziazione del proprio maestro attraverso la rūhāniyya di Ibn ${ }^{\mathrm{c}} \mathrm{Arab} \overline{\mathrm{i}} .{ }^{75}$ D'altra parte, ${ }^{\mathrm{c}} \mathrm{Abd}$ al-Ġan̄i al-Nābulusī, che dichiara di 'essere cresciuto succhiando dal seno [di Ibn ${ }^{\mathrm{c}} \mathrm{Arab} \overline{1}$ ] attraverso i suoi libri e le sue opere', racconta di avere sognato di essere il figlio di Ibn ${ }^{c} A r a b \overline{1} .{ }^{76}$ Lo stesso Ibn

71 Cfr. J. Baldick, 'Uwaysiyya,' $E I^{2}$; M. Chodkiewicz, 'Rūḥāniyya,' $E I^{2}$; idem, 'Note complémentaire', 54-8; F. Meier, 'An Exchange of Letters', 60-1, 74.

72 Cfr. J. ter Haar, 'The Importance of the Spiritual Guide'.

73 A. Schimmel, Die Träume des Kalifen, 179.

74 P. Nwyia, Ibn 'Abbād, xlviii.

75 D. Gril, 'De la khirqa à la țarīqa', 74.

76 Al-Ġazzī, al-Wird al-unsī, f. 184a. 
${ }^{\mathrm{c}}$ Arabī, all'inizio di un suo compendio delle dottrine di Ibn Ḥazm, racconta di avere scoperto la grandezza di questo autore attraverso una visione prima ancora di sapere chi fosse e di leggerne le opere. ${ }^{77}$ In altri termini, l'incontro con l'autore di un testo nel mondo immaginale ristabilisce fra lui e il suo lettore il rapporto personale proprio dell'oralità.

La tendenza a vedere il libro come una persona ha radici remote che risalgono alla teologia del logos. La riflessione sulla parola divina come mediatrice fra trascendenza e immanenza è comune alle tre religioni monoteiste, anche se il logos nell'islam e nel giudaismo ha finito col cristallizzarsi nella forma di un libro piuttosto che di una persona. ${ }^{78} \mathrm{Il}$ libro ipostatizzato si presta però anche nell'islam e nel giudaismo a essere rappresentato in forma umana, un fenomeno che ha trovato sviluppi particolarmente notevoli nella mistica. Così, in un capitolo dello Zohar, la Tora è descritta come una fanciulla nascosta, che si 'rivela faccia a faccia' solo al suo vero amante, ${ }^{79}$ mentre il Corano si manifesta a Ibn ${ }^{\mathrm{c}} \mathrm{Arab} \overline{1}$ in forma di fanciullo nella visione inaugurale delle Futūḥăt, ordinandogli di 'sollevare i suoi veli e leggere ciò che racchiudono le sue iscrizioni' ${ }^{80}$

L'iniziazione personale attraverso un autore del passato può essere insomma considerata un riflesso dell'ipostatizzazione del libro rivelato, parola vivente la cui sacralità si riverbera anche sui libri che derivano da essa, come in linea di principio lo sono quelli scritti dagli 'eredi del Profeta'. ${ }^{81}$

77 I. Goldziher, The Zāhirīs, 170-1.

78 Cfr. D.A. Madigan, The Qur'ân's Self-Image, 123-4, 182-3; A. Neuwirth, Der Koran als Text, 158-68; D. Boyarin, Border Lines, 89-127.

${ }^{79}$ Zohar, 125; cfr. anche E. Wolfson, 'The Body in the Text'.

80 M. Chodkiewicz, Océan, 126. Sull'identificazione del Corano con 1'Uomo Perfetto si veda ibid., 50-4, 124-8; cfr. anche al-Ǧîlì al-Insān al-kāmil, 2: 1389 (al-kitāb huwa l-insān al-kāmil); R.A. Nicholson, Studies, 104, 138-40. La rappresentazione del Corano in forma umana non è in ogni caso esclusiva della mistica; cfr. al-Ġazālī, Kitāb al-Durra, 119: 'Il Giorno della Resurrezione, il Corano verrà nell'immagine di un uomo, bello di volto e di carattere, intercederà e sarà esaudito'.

${ }_{81}$ Per questo motivo, mi sembra poco convincente vedere nella scrittura mistica, come fa E. Moosa leggendo al-G̈azālī alla luce di J. Derrida, il progetto di emanciparsi dal 'logocentrismo' della cultura islamica e dalla 'metafisica della presenza', ovvero dalla 'fiction della referenza diretta' (E. Moosa, Ghazālì, 96, $100,112)$. Sulla sacralità dei 'libri' nell'islam si veda in generale A.M. Piemontese, 'Sistema e strumenti dell'Islam'. Sui testi di 'Abd al-Qādir, Ibn 
Le controversie in Yemen e in al-Andalus

A partire dal VII/XIII secolo, con l'espansione delle confraternite e la sempre maggiore penetrazione del sufismo a tutti i livelli della società, il pubblico dei lettori di testi sufi si allarga. I vari generi della letteratura sufi rispondono alle esigenze di diverse tipologie dei lettori - devozione, edificazione morale o ricerca intellettuale. La diffusione della letteratura sufi si accompagna a sua volta a un incremento della pratica della lettura privata. In ambito sufi, come segnala la tradizione biografica, i kutub al$m u^{c} \bar{a}$ mala possono sostituirsi al maestro già nel periodo classico, un fenomeno che diventa sempre più frequente nei secoli successivi. ${ }^{82} \mathrm{Nel}$ tardo medioevo, questi testi, ormai parte delle biblioteche della madrasa, sono letture standard dei pii ${ }^{c} u l a m \bar{a}^{p}$, in funzione di un perfezionamento morale che non comporta necessariamente un'affiliazione al sufismo. ${ }^{83}$ Anche i kutub al-mukāšafa sono studiati al di fuori dell'ambito strettamente sufi. Come si è visto, il dizionario specializzato di al-Qāšān̄ī presuppone un pubblico di lettori-filosofi che continuano a coltivare nell'oriente islamico la tradizione avicenniana. D'altra parte, in Andalus, il libro sull'amore mistico del celebre storico e visir Ibn al-Hatīi (m. 776/1375), la Rawdat al-tacrīf bi-l-hubb al-šarīf, è un esempio dell'integrazione della mistica speculativa e della falsafa nella letteratura profana da parte di un letterato che non è lui stesso un sufi. ${ }^{84}$

Come testimoniano i dibattiti della fine del VIII/XIV secolo, questa evoluzione storica ha suscitato vive reazioni fra i contemporanei. Le controversie non riguardano solo il valore educativo della lettura privata, ma la stessa legittimità dei 'libri sullo svelamento', o dei 'libri sulla

${ }^{\mathrm{c}}$ Arabī e Rūmī come libri direttamente ispirati dalla realtà sottile del Profeta, cfr. H. Algar, 'The Centennial Renewer', 305-6.

82 Cfr. H. Landolt, Correspondance, 9-10 (a proposito di Simnān̄̄, m. nel 736/1336); Ibn ' ${ }^{\mathrm{C}} \mathrm{Abbād,} \mathrm{Lettres,} \mathrm{191;} \mathrm{al-Ša}{ }^{\mathrm{c}} \mathrm{rān} \overline{1}$, Lața $^{\mathrm{a}}$ if, 84-5. Ibn ${ }^{\mathrm{c}} \mathrm{Arab} \overline{1}$ peraltro avrebbe affermato che il suo manuale di disciplina spirituale intitolato Mawāqic al-nuǧūm 'può dispensare dal maestro, anzi è il maestro ad averne bisogno' (yuğnī can al-ustād, bal al-ustād muhtāăg ilayhi): cfr. Nābulusī, Rusūh, f. 189b-190a (dalle Futūhāt, bāb al-țahāra).

83 Ibn Ğamā $\bar{a}^{\mathrm{a}}$, Tadkira, 76-7, menziona tra le regole di condotta del maestro la purificazione dai vizi interiori tipici dei dotti, come l'invidia, la superbia, l'ipocrisia. La medicina che li cura si trova nei 'libri della delicatezza' (kutub alraqā̄iq), come l'Ihya $\bar{a}^{\supset}$, il Qūt al-qulūb di al-Makkī e la $R i^{c} \bar{a} y a$ di al-Muhāāsibī. Si veda anche R. Pérez, 'Introduction', 28; M. Fierro, 'Opposition to Sufism', 193.

84 A. Knysh, Ibn ${ }^{c}$ Arabi, 176-9. 
haqīqa'. Per quest'ultimo aspetto, il dibattito intorno al libro si colloca nel contesto delle polemiche dottrinali intorno alla scuola di Ibn ${ }^{\mathrm{c}} \mathrm{Arab} \overline{\mathrm{i}}$.

Questo è particolarmente evidente nelle controversie in Yemen. Qui, tra la fine del VIII/XIV secolo e l'inizio del IX/XV, i sultani della dinastia rasulide (1235-1454) avevano adottato una politica religiosa risolutamente favorevole al sufismo, facendo della loro capitale Zabīd un centro importante di attività sufi. ${ }^{85} \mathrm{I}$ sovrani privilegiarono $\mathrm{i}$ rappresentanti della scuola di Ibn ${ }^{\mathrm{c}}$ Arabī, come lo šayh Ismā ${ }^{c} \bar{l}$ al-Ğabartī (m. 806/1403), che fu il più prossimo amico e consigliere del sultano alAšraf Ismā̄īl (r. 1376-1400), e Aḥmad ibn Ab̄̄ Bakr al-Raddād (m. 821/1417-1418), che divenne genero del sultano al-Nāșir Aḥmad (m. 827/1424) e fu da lui nominato $q \bar{a} d \bar{l} \bar{\imath}$ supremo dello Yemen rasulide. ${ }^{86}$

La protezione ufficiale della scuola di Ibn ${ }^{\mathrm{c}} \mathrm{Arabī}$ suscitò lo scontento di numerosi ${ }^{c}$ ulam $\bar{a}^{\supset}$, alimentando una serie di violente polemiche che si trascinarono per decenni e che costituiscono un capitolo importante della storia politico-religiosa dello Yemen medievale. In queste polemiche, il libro ha un ruolo fondamentale. Infatti, i libri di Ibn ${ }^{\mathrm{c}}$ Arabī e dei suoi commentatori, base della dottrina dell' 'unità dell'essere', erano diventati 'una fonte di identità per la comunità sufi locale' ${ }^{87}$ Per gli avversari, l'origine della corruzione morale e dottrinale della loro epoca va cercata innanzitutto nei libri di Ibn ${ }^{\mathrm{c}}$ Arabī e della sua scuola, ${ }^{88} \mathrm{di}$ cui raccomandano il divieto o la distruzione in vari avvisi legali. ${ }^{89}$ AlĞabartī, da parte sua, impone ai suoi discepoli lo studio dei Fuṣūṣ alhikam, esigendo che ne portino sempre una copia con sé, ${ }^{0}$ mentre Ibn al-Raddād, forte della sua autorità di giudice supremo, promuove una legittimazione ufficiale di $\mathrm{Ibn}^{\mathrm{c}} \mathrm{Arab} \overline{\mathrm{i}}$, sanzionando la diffusione dei suoi libri nelle zone sotto la sua giurisdizione. ${ }^{91}$ La promozione di queste letture non solo fra i sufi più avanzati, ma fra i novizi e il lettore comune, scandalizza gli avversari come un atto di audacia senza precedenti. ${ }^{92}$

È in questo contesto che ${ }^{\mathrm{c}} \mathrm{Abd}$ al-Karīm al-Ğìlī ha formulato una delle più articolate difese del valore formativo del libro nella mistica

85 Sui rasulidi e i sufi e la polemica intorno a Ibn ' ${ }^{\mathrm{c}}$ Arabī si veda ibid., 225-69; M. Chodkiewicz, 'Le procès posthume', 105-9.

86 A. Knysh, Ibn 'Arabi, 241-2, 248.

87 Ibid., 250.

88 Ibid., 243, 258.

89 Ibid., 253, 261, 265.

90 Ibid., 242.

91 Ibid., 255.

92 Ibid., 269. 
speculativa. Al-Ğ̄îlî, originario dell'India, trascorse gli ultimi decenni della sua vita in Yemen, dove si inserì nell'ambiente cosmopolita animato dal circolo di al-Ğabartī e dove morì all'inizio del IX/XV secolo. ${ }^{93}$ Il prologo del Libro sui gradi dell'essere, dove al-Ǧîlī celebra la funzione dei 'libri sulla haqīqa' nell'educazione dei sufi, illustra perfettamente il ruolo centrale del libro nella scuola di Ibn ${ }^{\mathrm{c}} \mathrm{Arab} \overline{\mathrm{i}}$, oltre a offrire un'importante testimonianza storica sui metodi pedagogici praticati dai sufi ibnarabiani alla sua epoca.

Per al-Ğîlīi, i libri sulla haqīqa sono il veicolo per eccellenza di un 'ilm salvifico che coincide con la conoscenza dell'"essere' e della sua unità fondamentale. Questa conoscenza va perseguita piuttosto attraverso lo studio che attraverso l'attesa passiva dell'illuminazione:

Mi è stato raccontato che il mio maestro Ismā $\bar{c}^{\mathrm{c}} \mathrm{l}$ al-Ğabartī disse a un allievo, uno dei miei fratelli: 'Studia i libri ( ${ }^{c}$ alayka bi-kutub) dello šayh Muhyȳi l-Dīn Ibn al-'Arabị!' 'Signore', rispose l'allievo, 'non è meglio che pazienti finché Dio stesso mi illumini attraverso la sua effusione?' Il maestro gli disse: 'Quello che vuoi aspettare è proprio ciò di cui lo šayh parla per te in questi libri'. ${ }^{94}$

La lettura è più produttiva della purificazione morale attraverso le pratiche devote, e può essere perseguita indipendentemente da esse. Infatti, lo studioso intelligente:

impara tutto dai libri e consegue attraverso di essi tutto ciò che si propone. Ho visto in questa nostra epoca un numeroso gruppo di gente di ogni razza-arabi, persiani, indiani, turchi, e altri ancora-raggiungere attraverso la lettura $\left(m u t ̦ \bar{a} l a^{c} a\right)$ dei libri sulla haqqīqa il livello dei [grandi] uomini, e realizzare attraverso di essi l'oggetto delle loro speranze. Chi poi in seguito aggiunge alla scienza $\left({ }^{c} i l m\right)$ e alla virtù la pratica e l'ascesi (sulūk wa-iğtihäd) diventa un perfetto, entre chi si ferma dopo avere conseguito la scienza diventa uno gnostico..$^{95}$

Al-Ğīlī ammette che l'accesso a questi libri possa essere limitato per motivi di prudenza o di opportunità pedagogica:

La proibizione della lettura dei libri sulla haqĩqa espressa a volte dalla gente di Dio nei riguardi di alcuni allievi è dovuta al fatto che la persona di

93 A. Knysh, Ibn 'Arabi, 232, 248-52. L'incertezza sulla data di morte di alĞîlì è dovuta alla scarsità di fonti biografiche su di lui. La data più comunemente fornita è l'832/1428, ma fonti manoscritte indicano l'811/1408 o l'826/1423: si veda M. Chodkiewicz, 'Le procès posthume', 105.

94 Al-Ǧìīi, Marātib, 9-10.

95 Ibid. 
scarsa comprensione può interpretare le parole degli autori in un senso diverso da quello che essi hanno inteso, per poi metterle in pratica e andare incontro alla perdizione; oppure egli rischia di perdere la vita compulsando i libri senza profitto. In tal caso è necessario che il maestro vieti la lettura affinché l'allievo si occupi di qualcos'altro che gli sia più utile. ${ }^{96}$

La lettura è però raccomandata anche ai principianti, che grazie ad essa superano i più anziani. I maestri infatti raccomandano agli allievi lo studio

per far loro percorrere più rapidamente grandi distanze e per facilitare loro le difficoltà del cammino, perché un aspirante può ottenere, attraverso [la comprensione] di una sola questione di questa nostra scienza, un risultato che non raggiungerebbe in cinquant'anni di ascesi (muğăhada).$^{97}[\ldots]$ 'Ho visto io stesso dei fanciulli (șibyān), fra i miei fratelli nella Via, arrivare in pochi giorni, attraverso la sola lettura di questi libri, a un livello superiore a quello raggiunto dagli uomini adulti (riğâl) in quaranta o cinquant'anni di ascesi, malgrado il fatto che erano stati questi adulti a iniziare alla Via quei fanciulli: infatti gli adulti si erano limitati alla pratica (sulukk), mentre i fanciulli erano passati alla lettura e alla comprensione dei libri sulla haqĩqa, così che i fanciulli sono diventati in senso proprio anziani, mentre i loro anziani maestri sono diventati fanciulli (șâra al-șibyān šuyūh fĭ l-haqūqa wa-l-šsuyūh lahum șibyān)' ${ }^{98}$

Il giovane lettore può superare il vecchio devoto perché attraverso la comprensione del testo diventa pari all'autore del passato:

Quando l'aspirante ricercatore comprende il senso della questione esposta in un libro e lo conosce, egli diviene l'eguale dell'autore nella conoscenza di quella questione (istawā huwa wa-mușannifuhu fì macrifat tilka almas ala), e consegue per mezzo di essa ciò che l'autore ha conseguito. Allora questa conoscenza gli appartiene (șārat lahu mulk) come appartiene all'autore. E così ogni volta che qualcuno prende una questione dai libri, se la comprende in modo esatto, è come se la prendesse dalla stessa fonte ( $m a^{c}$ dan) da cui l'ha presa l'autore. ${ }^{99}$

R. Atlagh, che ha visto in questo passo una delle più brillanti sintesi della nozione di originalità nel sufismo, ha osservato: 'Questa concezione della cultura cancella la nozione di autore e di plagio nella conoscenza

${ }_{96}$ Al-Ǧ̄ilīi, Marātib, 9.

97 Ibid.

98 Al-Ǧ̄ilīi, Marātib, 11.

99 Ibid., 8-9. Nel testo stampato manca la frase fa-inna al-āhid lahā min almacdan allad̄i ahada minhu mușannifuhu, che si trova però nella citazione di questo passo in al-Nābulusī, Kitāb al-rusūh, f. 192b. 
sufi e rende difficile la ricerca dell'originalità di un autore: il sapere sufi appartiene a tutto un gruppo e non a delle persone-autori'. ${ }^{100}$ In questa prospettiva, l'originalità non consiste in una innovazione individuale, ma nella capacità di accedere direttamente alla fonte divina della conoscenza: attraverso la comprensione del testo del santo, il lettore riattualizza l'ermeneutica spirituale della rivelazione che lo ha prodotto, emancipandosi dall' 'imitazione' passiva dei maestri.

La contrapposizione della 'comprensione' all'imitazione' corrisponde a una tensione fra una concezione aperta e una concezione chiusa del sapere che caratterizza in generale il conflitto fra discipline razionali e tradizionali. Ma il conflitto fra indipendenza intellettuale e fedeltà alla tradizione si ritrova anche all'interno delle tradizioni mistiche, nella tensione fra speculazione e trasmissione orale, ed è ugualmente presente nella dialettica fra autorità delle scuole e interpretazione personale nel diritto islamico. Il grado dell'iğtihād non implica infatti necessariamente l'aggiunta di una nuova dottrina, ma può limitarsi alla 'comprensione' delle dottrine dei predecessori. ${ }^{101}$

Una concezione del sapere come quella esposta da al-Ğîlì, per il quale i giovani superano i vecchi e i moderni possono stare alla pari con gli antichi, ${ }^{102}$ spiega bene la resistenza degli ${ }^{c}$ ulam $\bar{a}^{\supset}$ conservatori a questa scuola mistica, anche indipendentemente dall'ortodossia' dei suoi contenuti dottrinali. La scienza autorevole contenuta nei libri sulla haqīqa minaccia anche l'autorità dei 'vecchi' sufi: la relativa svalutazione delle pratiche di mortificazione e purificazione nel testo di al-Ǧîlī è infatti l'espressione di una tensione fra conoscenza e azione, o 'irfān e sulük, all'interno del sufismo. La sostanza della contesa intorno al libro nel sufismo sembra risiedere proprio in questo contrasto. Con la sua 'lode del libro', al-Ğîlī si propone di esaltare la conoscenza, ma non di sminuire il ruolo del maestro. Nella conclusione dice infatti:

Ti ho riferito tutte queste storie nell'introduzione di questo libro per farti comprendere il valore di questa scienza e l'elevatezza del suo rango, e ispirarti così il desiderio di conseguire questa nobile arte attraverso la lettura di questi libri, il loro studio, e la discussione su di essi con le persone che li conoscono, dovunque si trovino. Infatti, una di queste persone può insegnarti con una sola parola più di quanto possano insegnarti tutti i libri in

100 R. Atlagh, 'Le point et la ligne', 162-3.

101 Cfr. S. Pagani, 'The meaning', 20.

102 Cfr. anche al-Ǧìlī, Marātib, 8, dove l'autore contesta certi sufi secondo i quali nelle epoche tarde l'ispirazione è quasi scomparsa, suggerendo che essa è semmai diventata invisibile, perché Dio non cessa mai di manifestarsi. 
una vita intera [...]. La lettura dei libri sulla haqiqqa, secondo coloro che comprendono la realtà delle cose, è superiore alle opere di devozione dei praticanti, ma la frequentazione (muğălasa) della gente di Dio e l'educazione ( $\left.t a^{\circ} a d d u b\right)$ che si riceve da essa è superiore alla lettura di tutti i libri messi insieme. ${ }^{103}$

Lo stesso al-Ǧîlī ha celebrato altrove il proprio maestro, Ismācīl alĞabartī, in termini iperbolici. In seguito a una visione ricevuta a Zabīd nel 796/1393, avrebbe infatti riconosciuto in lui la manifestazione del Profeta, ovvero dell'Uomo perfetto, che si rivela in un'unica persona in ogni generazione. ${ }^{104}$ Per questo motivo, al-Ğîli fu accusato dagli avversari, insieme ad altri seguaci di al-Ğabartī, di 'adorare' il maestro. ${ }^{105}$ 'Adorazione' del maestro ed esaltazione del libro non sono contraddittorie: al-Ǧîlī afferma infatti che l'Uomo perfetto, come espressione del logos divino, si identifica con il Corano. ${ }^{106}$

Alla fine del XI/XVII secolo, il testo di al-Ğîlī sui libri è stato copiato quasi integralmente da ${ }^{\mathrm{c}} \mathrm{Abd}$ al-Ğanī al-Nābulusī in un opuscolo che difende il ruolo del libro nell'educazione sufi. Rifacendosi innanzitutto a al-Ġazālì, anche al-Nābulusī mette al centro della sua argomentazione la superiorità della conoscenza sulla pratica, nel contesto di una polemica rivolta al tempo stesso contro i dottori essoterici e contro i maestri delle confraternite. Al-Nābulusī ammette qui esplicitamente che del maestro si possa fare a meno, sebbene questo non sia auspicabile di per sé, ma sia dovuto all'indegnità dei contemporanei. ${ }^{107}$ Infatti, al-Nābulusī definisce altrove gli autori morti i cui libri leggeva durante la sua reclusione come 'i viventi', e i contemporanei viventi che aveva scelto di abbandonare come 'i morti'. ${ }^{108}$

Negli stessi anni delle polemiche yemenite, un altro grande dibattito intorno alla lettura dei libri sufi si è svolto in Andalus e in Maghrib. Nel

103 Al-Ǧ̄̄lī, Marātib, 11-12.

104 Al-Ǧìlī, al-Insān al-kāmil, 2: 74; cfr. A.R. Nichloson, Studies, 105.

105 A. Knysh, Ibn ${ }^{c}$ Arabi, 251.

106 Al-Ǧîlī, al-Insān al-kāmil, 2: 138-9 (al-kitāb huwa l-insān al-kāmil); cfr. la quasi identica affermazione di Ibn 'Arabī: 'L'Uomo universale (al-insān alkullī) è il Corano': M. Chodkiewicz, Océan, 125. Nello stesso testo, 1: 124, alĞîlī afferma che il Figlio della trinità cristiana va interpretato nel senso di Libro (al-murād bi-l-ibn al-kitāb); cfr. A.R. Nicholson, Studies, 140.

107 Al-Nābulusī, Kitāb al-rusūhn. Sulle prese di posizione di al-Nābulusī intorno alla questione del libro e del maestro cfr. B.R. von Schlegell, Sufism, 198-9; S. Pagani, 'Scholasticism', 285-6; S. Akkach, 'Abd al-Ghani alNabulusi, 34-5.

108 S. Akkach, Letters, xi. 
774/1372, il libro del visir Ibn al-Hatịib sull'amore mistico era stato bruciato pubblicamente nella piazza del mercato di Granada, alla presenza di eminenti ${ }^{c}$ ulam $\bar{a}^{ }$. ${ }^{109}$ Nella stessa città, e nello stesso anno, la comunità sufi fu scossa da un'aspra controversia intorno alla questione se i libri possano sostituire il maestro. Secondo la tarda testimonianza del sufi šādilita Aḥmad Zarrūq (m. a Fez nell'899/1493), la disputa fu così violenta che i contendenti giunsero a prendersi a colpi di scarpa. ${ }^{110} \mathrm{Il}$ dibattito coinvolse anche i giuristi. Il grande teorico del diritto Abū Ishāa al-Šățibī (m. 790/1388) scrisse una memoria della controversia, che inviò, insieme alla richiesta di un parere, al giurista mālikita Aḥmad alQabbāb (m. 1376) e al sufi šādilita Ibn ${ }^{\mathrm{c}}$ Abbād di Ronda. La memoria di al-Šățibī è conservata integralmente nello Šif $\bar{a}^{\jmath}$ al-s $\bar{a}^{\jmath} i l$ wa-tahd $\underline{i} b$ almasă $\bar{a}^{\curvearrowright} i l$ di Ibn Haldūn (m. 780/1406), ${ }^{111}$ che, pur non essendo stato consultato direttamente, interviene con quest'opera in margine al dibattito. La trascrizione commentata della controversia è preceduta da una lunga introduzione in cui Ibn Haldūn espone in una prospettiva critica la storia e le dottrine del sufismo.

Il dossier relativo a questa controversia è stato letto dalla maggior parte degli storici moderni nel quadro del conflitto fra giuristi e sufi, ovvero fra il sufismo dei dotti e il sufismo popolare. ${ }^{112}$ Questo punto di vista è giustificato dalla situazione del Maghrib nel periodo marinide (1258-1465), dove, nel contesto della rivalità fra ${ }^{c} u l a m \bar{a}^{\supset}$ mālikiti e guide carismatiche delle confraternite, i giuristi si oppongono alla venerazione degli šayh. Questo schema interpretativo però impedisce di cogliere le complesse sfumature del dibattito, facendo sorgere notevoli contraddizioni. ${ }^{113}$

109 Cfr. R. Pérez, 'Introduction', 39-40; A. Knysh, Ibn 'Arabi, 174.

110 Zarrūq, ${ }^{C}$ Umdat al-murīd. Nel manoscritto che ho consultato è scritto che la controversia si svolse bayna fuqahă $\bar{a}^{\supset}$ al-Andalus, ma bisogna probabilmente leggere fuqara $\bar{a}^{\jmath}$ : cfr. P. Nwyia, Ibn ' $A b b \bar{a} d$, xlviii, e R. Pérez,'Introduction', 14, che si basano su altri manoscritti della stessa opera. Zarrūq parla della controversia andalusa anche in $\operatorname{Qawa}^{c} i d$, 54-5 (cap. 67).

111 Cfr. Ibn Haldūn, Šifă ${ }^{3}$ al-sāa $i l$, che contiene un'appendice con le risposte di al-Qabbāb e Ibn ' Abbād, e anche una breve risāla sullo stesso argomento del letterato marocchino Yūsī (m. 1102/1691). Del testo di Ibn Haldūn esiste un'ottima traduzione francese ampiamente annotata a cura di R. Pérez: Ibn Haldūn, La voie et la loi.

112 Mahdi, 'The Book and the Master'; R. Pérez, 'Introduction'; V. Cornell, 'Faqīh versus Faqīir', 202-3.

113 Gli avversari del sufismo popolare andrebbero identificati secondo Mahdi con i sostenitori dell'indispensabilità del maestro ('The Book and the Master', 
Una diversa prospettiva è stata adottata da P. Nwyia in uno studio esemplare del 1961. Dopo avere accennato alla diffusione dell'apprendimento attraverso i libri tra gli studenti di diritto nel Maghrib della seconda metà del VIII/XIV secolo, Nwyia osserva: 'ce qui signifie que d'une civilisation orale, on est en voie de passer à une civilisation du livre. Et si ce passage est loin encore d'être réalisé en ce qui concerne les sciences légales, il semble par contre que les soufis aient fait quelques pas dans cette voie'. ${ }^{114}$ Nella sua sintesi della controversia, Nwyia si sofferma quindi sulla questione essenziale di quali libri sufi fossero studiati e contestati nel Maghrib di questo periodo. ${ }^{115}$

In effetti, il dossier relativo alla controversia di Granada è una testimonianza storica di primo piano sul ruolo del libro nel sufismo medievale, e in quanto tale può essere affiancata, al di là delle specificità locali, alla controversia yemenita. Come i dibattiti contemporanei in Yemen, anche quelli dell'occidente musulmano possono essere letti come il risultato di un duplice contrasto: da un lato l'opposizione legale contro la diffusione dei 'libri sullo svelamento', dall'altro la tensione interna al sufismo fra la conoscenza, basata sui libri, e l'azione, basata sull'esempio dei maestri.

L'opposizione legale contro la diffusione dei 'libri sullo svelamento' è chiarita dagli interventi di Aḥmad al-Qabbāb e di Ibn Haldūn. L'argomentazione comune a entrambi è che mentre nel perfezionamento morale si può fare a meno del maestro, affidandosi ai manuali sufi sulla scienza pratica (mu'āmala), il maestro è indispensabile nella ricerca dello 'svelamento' (mukāšafa), perché questa via è piena di pericoli e i libri che ne parlano, lungi dall'essere utili, sono dannosi. Persino i libri di al-Ġazālī, secondo al-Qabbāb, dovrebbero essere espurgati di tutti i passaggi in cui si parla delle realtà del mondo invisibile; un santo maghrebino del secolo precedente li aveva del resto condannati insieme a quelli di al-Qušayrī, dichiarando che avrebbe volentieri buttato a mare questi ultimi. ${ }^{116}$

9), e secondo R. Pérez con i sostenitori della sua non indispensabilità ('Introduction', 31-2; 47-8 e 259 n. 29). M. Mahdi presuppone che i libri in questione siano 'manuali popolari', ma dalla controversia questo non appare chiaramente.

114 P. Nwyia, Ibn ${ }^{c} A b b \bar{a} d$, xlviii.

115 Ibid., xlviii-1x.

116 Cfr. P. Nwyia, Ibn 'Abbād, 1 e lvi; R. Pérez, 'Introduction', 34, 51, 259; M. Mahdi, 'The Book and the Master', 5. Cfr. il testo della fatwā di al-Qabbāb in Ibn Haldūn, Šifă al-sāa $\bar{a}^{\jmath} l, 203$. 
Ibn Haldūn, da parte sua, concentra la sua polemica contro le deviazioni dottrinali dei libri sullo svelamento scritti dalle scuole 'moderne' della 'teofania' (tağallī) e dell'"unicità' (wahda), illustrate rispettivamente da $\mathrm{Ibn}{ }^{\mathrm{c}} \mathrm{Arab} \overline{\mathrm{l}}$ e dall'altro mistico andaluso $\mathrm{Ibn} \mathrm{Sab}^{\mathrm{c} \overline{\mathrm{i}} \mathrm{n}}$ (m. 668/1269 o 669/1271). ${ }^{117}$ Chi aspira a intraprendere il cammino dello svelamento, se non riesce a trovare un maestro, piuttosto che studiare questi libri, farebbe meglio a rinunciare del tutto all'impresa. ${ }^{118}$ L'argomentazione di Ibn Hualdūn si discosta dal discorso puramente legalista perché la sua critica al sufismo si basa anche sulla sua adesione alle scienze razionali, che gli fa riprendere le obiezioni epistemologiche contro la conoscenza mistica tipiche dei filosofi. ${ }^{119}$ Un punto di vista esclusivamente legalistico è adottato comunque da Ibn Haldūn in una fatwa posteriore, risalente al suo periodo egiziano, in cui prescrive che $\mathrm{i}$ libri di Ibn ${ }^{\mathrm{c}} \mathrm{Arabī}$ e di Ibn $\mathrm{Sab}^{\mathrm{c}} \overline{\mathrm{i}} \mathrm{n}$ siano dati alle fiamme o lavati con l'acqua. ${ }^{120}$ In ogni caso, sostenere la necessità del maestro nel cammino verso lo 'svelamento' equivale per Ibn Haldūn a vietarne la trasmissione scritta.

Mentre le risposte di al-Qabbāb e di Ibn Haldūn esprimono l'opposizione legale contro la mistica speculativa, l'intervento di Ibn ${ }^{\mathrm{c}} \mathrm{Abbād} \mathrm{di} \mathrm{Ronda} \mathrm{illustra} \mathrm{bene} \mathrm{le} \mathrm{tensioni} \mathrm{interne} \mathrm{al} \mathrm{sufismo.}{ }^{121} \mathrm{Ibn}$ ${ }^{\mathrm{c}} \mathrm{Abbād}$, che ha esercitato il suo insegnamento soprattutto per lettera una modalità che Ibn Haldūn rigetta espressamente, ${ }^{122}$ - afferma all'inizio del testo di essersi formato sui libri. ${ }^{123}$ Ciò nonostante, Ibn ${ }^{\mathrm{c}}$ Abbād prende le distanze da entrambe le fazioni contendenti ed evita di pronunciarsi in termini categorici, perché ritiene che una tale questione non dovrebbe essere oggetto di una decisione legale. La sua risposta è così sfumata che è stata intesa diversamente dagli studiosi moderni: per esempio, secondo M. Mahdi, Ibn ${ }^{\mathrm{c}}$ Abbād si pronuncia 'in pratica' per $l^{\prime}$ indispensabilità del maestro, ${ }^{124}$ mentre F. Meier sottolinea che per Ibn

\footnotetext{
117 Ibn Haldūn, La voie et la loi, 180, 183.

118 Ibid., 245.

119 Cfr. J.W. Morris, 'An Arab Machiavelli?'.

120 Cfr. la trad. del testo in Ibn Haldūn, La voie et la loi, 251-4.

121 Per i testi si veda Ibn ${ }^{\mathrm{c}}$ Abbād, Lettres, 130-40, 190-204. Il testo della prima lettera è parafrasato da $\mathrm{P}$. Nwyia nel suo $I b n^{c} A b b \bar{a} d, 209-13$.

122 Ibn Haldūn, La voie et la loi, 247.

123 Ibn ${ }^{\mathrm{c}}$ Abbād, Lettres, 191. E' possibile che Ibn ${ }^{\mathrm{c}}$ Abbād, pur essendo un'autorità nella tradizione šâdilita, non avesse ricevuto un'iniziazione formale alla țarīqa: cfr. S. Kugle, 'Usūlī Sufis', 185-6.

124 'The Book and the Master', 6.
} 
'Abbād il libro può 'in pratica' sostituire il maestro. ${ }^{125}$ Quest'ultimo punto di vista è confortato dalla sintesi di Aḥmad Zarrūq:

La risposta del mio signore Ibn ${ }^{\mathrm{C}} \mathrm{Abbād}$ è che la cosa dipende dagli individui e dalle situazioni: il maestro insegnante ( $\check{s} a y h$ al-taclimm) può essere sostituito dai libri per chi è dotato di intelligenza e ragione, mentre il maestro educatore (šayh al-tarbiya) è obbligatorio solo per lo stupido, anche se certamente consigliabile anche agli altri. ${ }^{126}$

Il punto centrale dell'intervento di Ibn ${ }^{\mathrm{c}} \mathrm{Abbād} \mathrm{è} \mathrm{appunto} \mathrm{la} \mathrm{distinzione} \mathrm{fra}$ 'maestro insegnante' e 'maestro educatore'. Si tratta di un punto di grande importanza nella storia del sufismo, dato che l'ascesa del 'maestro educatore' è una tappa decisiva nella formazione delle confraternite. ${ }^{127}$ Ibn 'Abbād descrive l'imposizione del 'maestro educatore' come un'innovazione 'moderna', cioè una deviazione dal sano sufismo delle origini, dovuta a un'abusiva enfasi sulla pratica piuttosto che sulla conoscenza. ${ }^{128}$ Così, Ibn ' $\mathrm{Abbād} \mathrm{critica} \mathrm{l'aspetto} \mathrm{istituzionale}$ dell'evoluzione 'moderna' del sufismo, al contrario di Ibn Haldūn, che ne critica l'aspetto dottrinale, ma include un 'maestro educatore' 'moderno' come ${ }^{c}$ Umar al-Suhrawardī nella sua lista di letture consigliate. ${ }^{129}$

Ciò che è decisivo, nella distinzione fra i due tipi di maestro, e dunque anche nella questione della loro necessità, è il contenuto dell'insegnamento: lo šayh al-taclìm, come dice il suo stesso nome, deve trasmettere una conoscenza, mentre l'educazione impartita dallo šayh altarbiya riguarda la sfera pratica. La questione di fondo è dunque in questo testo, come in quello contemporaneo di al-Ǧîlīe, il primato della conoscenza o dell'azione. Per Ibn ${ }^{\mathrm{c}} \mathrm{Abbād}$, il nucleo autentico e originario del sufismo è la conoscenza, mentre la dimensione pratica e rituale istituzionalizzata dalle confraternite è uno sviluppo secondario, concomitante con l'attribuzione di un'indebita autorità al 'maestro educatore'. Al contrario dell'educazione pratica, la conoscenza è essenziale e va raggiunta con ogni mezzo. Il mezzo privilegiato sarebbe il maestro, ma in sua assenza si può ricorrere anche al libro: anzi maestro e libro sono praticamente equiparati in quanto il libro, come fonte autorevole di conoscenza, è un autentico 'sostituto' del maestro. ${ }^{130}$ Sia il

\footnotetext{
125 'Khurāsān', 192.

126 Aḥmad Zarrūq, ' Umdat al-murīd, f. 48b.

127 Cfr. F. Meier, 'Khurāsān'.

128 Cfr. Ibn 'Abbād, Lettres, 194.

129 Ibn Haldūn, La voie et la loi, 174.

130 Cfr. Ibn ' Abbād, Lettres, 192-3.
} 
libro sia il maestro sono semplici 'mezzi', o 'cause seconde', di una illuminazione che dipende in realtà solo da Dio. ${ }^{131}$ Ma questo non significa che si debba stare fermi ad aspettare passivamente, rinunciando a mettersi in cammino in assenza di un maestro. ${ }^{132}$ Anche su questo punto, la posizione di Ibn ${ }^{\mathrm{c}} \mathrm{Abbād} \mathrm{è} \mathrm{contraria} \mathrm{a} \mathrm{quella} \mathrm{di} \mathrm{Ibn} \mathrm{Haldūn,} \mathrm{che}$ raccomanda di rinunciare a incamminarsi senza un maestro.

Mi pare che nelle sue linee essenziali il ragionamento di Ibn ${ }^{\mathrm{c}} \mathrm{Abbād}$ sia identico a quello di al-Ğîlì: il punto centrale è che il sufismo autentico è un ${ }^{\mathrm{c}} \mathrm{ilm}$ salvifico accessibile anche solo attraverso i libri, aggirando al tempo stesso l'autorità dei maestri delle confraternite e la censura dei giuristi. La differenza fra $\mathrm{i}$ due autori sta essenzialmente nelle letture consigliate: mentre per al-Ğîlī queste sono in generale i 'libri sulla haqīqa' e in particolare Ibn 'Arabī, per Ibn ' ${ }^{\mathrm{c}} \mathrm{Abbād} \mathrm{sono} \mathrm{i} \mathrm{classici} \mathrm{della}$ tradizione šădilita e in particolare Ibn ${ }^{\mathrm{c}} \mathrm{A} t \bar{a}^{\circ} \mathrm{A}$ Allāh. ${ }^{133} \mathrm{Il}{ }^{\mathrm{c}} \mathrm{ilm}$ coltivato nella confraternita šādilita si differenzia per molti aspetti, relativi allo stile espositivo forse ancor più che ai contenuti dottrinali, da quello dei sufifilosofi. ${ }^{134}$ Ibn ${ }^{\mathrm{c}} \mathrm{Abbād}$ in ogni caso, a differenza di altri sufi, oltre che di molti giuristi, non è un censore: lo dimostra il suo atteggiamento verso Ibn $\mathrm{Sab}^{\mathrm{c}} \overline{\mathrm{i}} \mathrm{n}$, che si guarda bene dal condannare pur ritenendo personalmente che non valga tutto lo sforzo che la sua lettura richiede. ${ }^{135}$

Sulla questione del libro e del maestro, Ibn ${ }^{\mathrm{c}} \mathrm{Abbād}$ è il principale ispiratore, un secolo dopo, di Ahmad Zarrūq, un altro maestro šādilita che ha prestato particolare attenzione alla questione. Zarrūq, come Ibn ${ }^{c}$ Abbād, tende a ridimensionare l'autorità carismatica del maestro sul discepolo e si considera un 'maestro insegnante' piuttosto che un 'maestro educatore'. La sua scarsa stima per i maestri contemporanei gli fa peraltro ammettere che la guida dei libri possa dispensare da un maestro vivente. ${ }^{136}$ Zarrūq giunge a distinguere dieci tipologie di sufi in base ai loro libri di riferimento. Anche i libri di Ibn ${ }^{\mathrm{c}} \mathrm{Arab} \overline{\mathrm{i}}$ hanno il loro

131 Ibn ${ }^{\mathrm{c}}$ Abbād, Lettres, 197-8. Un'idea frequente nella tradizione sufi, da accostare alla tesi del De magistro di Agostino.

132 Ibid., 133, 201.

133 Ibid., 121-2; cfr. anche Aḥmad Zarrūq, ${ }^{c}$ Umdat al-murīd, f. 46a-47b. Sul ruolo centrale della meditazione sulle Hikam di Ibn ${ }^{\mathrm{c}}$ Ațāo ${ }^{\circ}$ Allāh nella tradizione sufi che risale a Ibn 'Abbād si veda anche S. Kugle, 'Usūlī Sufis', 184. Sull'importanza dello studio dei classici del sufismo sin dalle origini della Shādhiliyya, cfr. D. Gril, 'L'enseignement d'Ibn ' Atā̄ Allāh'.

134 É. Geoffroy, 'Entre ésoterisme et exotérisme'.

135 Cfr. P. Nwyia, Ibn ${ }^{c} A b b \bar{a} d$, lviii.

136 Cfr. S. Kugle, Rebel, 151-4; idem, 'Usūlī Sufis', 190-6; F. Meier, 'Khurāsān', 219. 
posto in questa lista, dove servono a identificare la tipologia del 'saggio' (hakim). Ma il sufi davvero perfetto è quello che fa riferimento ai libri della confraternita šădilita. ${ }^{137}$ Poiché per Zarrūq il sufi perfetto è il giurista che fonda la propria condotta sui testi rivelati, la sua valorizzazione della lettura individuale si ricollega allo stesso tempo alla tradizione intellettuale del sufismo e alla tendenza al ritorno alle fonti di un muğtahid riformista.

\section{Conclusione}

La letteratura sufi, per la sua varietà e per la sua diffusione a vari livelli della società, potrebbe costituire un oggetto di studio privilegiato in una storia della lettura nell'islam premoderno. Ma il ruolo del libro sufi nella storia sociale e intellettuale dell'islam ha cominciato a essere esplorato in modo abbastanza sistematico solo per quanto riguarda il XIII/XIX secolo, il momento di passaggio dalla cultura manoscritta alla cultura della stampa nel mondo islamico. ${ }^{138}$

Sulla base delle fonti prese in esame in questo articolo, sembra comunque possibile affermare che il sufismo abbia avuto un ruolo importante nella promozione della lettura privata nell'ambito delle scienze religiose. A partire dal VII/XIII secolo, la diffusione dell'opera di Ibn ${ }^{\mathrm{c}}$ Arabī ha certamente incoraggiato la valorizzazione del libro e dello studio individuale. Anche nel caso dell'ebraismo, come si è visto, alcuni storici ritengono che la nascita di una letteratura mistica nel VII/XIII secolo abbia svolto un ruolo particolarmente importante nella transizione da una cultura orale a una cultura del libro.

La trasformazione delle pratiche di lettura e della forma del manoscritto prima dell'avvento della stampa è stata oggetto di un'attenzione particolare da parte degli storici dell'Europa medievale e della prima età moderna, in reazione alla tradizione storiografica che ha attribuito alla stampa la rivoluzione decisiva nelle pratiche di lettura. ${ }^{139}$ Secondo P. Saenger, tali trasformazioni potrebbero essere state in parte il risultato dell'imitazione dei manoscritti arabi negli scriptoria spagnoli dove si tradussero testi filosofici e scientifici dall'arabo. ${ }^{140}$

Comunque sia, è certo che il libro silenzioso è per eccellenza il libro tradotto. Proprio per questo, nella civiltà islamica classica, che è stata inaugurata da una straordinaria attività di traduzione, la trasmissione orale

137 Cfr. A. Zarrūq, Qawācid, 51 (cap. 60).

138 Cfr. R. Chih-Mayeur-Jaouen-R. Seesemann (eds.), Sufism, Literary Production and Printing.

139 S. Landi, 'Stampa', 52.

140 P. Saenger, Space Between Words, 124-5. 
e la lettura privata hanno coesistito sin dall'inizio. Nel periodo classico però la 'lode del libro', cioè la valorizzazione del suo autonomo valore formativo, è legata soprattutto all'adab e alle 'scienze straniere', mentre le scienze religiose hanno insistito soprattutto sulla funzione pedagogica della trasmissione orale.

Nelle scienze religiose, la contrapposizione fra il libro e il maestro è in buona parte ideologica, perché la lettura privata è collegata a valori che minacciano la continuità della tradizione, come l'indipendenza intellettuale e il rovesciamento delle gerarchie tradizionali basate sull'anzianità o l'antichità. La dialettica fra fedeltà alla tradizione e confronto diretto con i testi è un dato strutturale in una cultura al tempo stesso orale e scritta. Il sufismo, parte integrante della cultura religiosa medievale, ha contribuito a rafforzare entrambi i poli di questa dialettica. Se il modello di educazione sufi è servito a confermare il principio dell'ubbidienza dovuta al maestro nella madrasa tardo-medievale, ${ }^{141}$ l'insistenza sul valore formativo del libro da parte di alcuni autori sufi si accompagna al recupero della cultura filosofica negli studi teologici e alla promozione di un'ermeneutica 'rinnovata' delle fonti del diritto. Contrariamente a quanto riteneva Louis Massignon, la scuola di Ibn 'Arabī non ha riservato 'l'apanage de la mystique, science ésotérique qui ne doit pas être divulguée, à des cercles initiatiques fermés'. ${ }^{142}$ Le reazioni di Ibn Haldūn e di altri autori dell'epoca mostrano infatti la rilevanza culturale e politica della diffusione dei 'libri sullo svelamento' prodotti da autori 'moderni' come Ibn ${ }^{\mathrm{c}} A r a b \overline{1}$ e Ibn Sab'īn. L'ulteriore espansione della letteratura prodotta dalle confraternite nel periodo ottomano meriterebbe di essere studiata nella prospettiva della storia sociale di una prima modernità islamica che, malgrado differenze di grande importanza, come la mancata adozione della stampa, presenta paralleli inesplorati con la storia europea. ${ }^{143}$

141 Ibn Ğamāc a, Tadkira, 117, cita a questo proposito al-Ġazālī ('l'errore del maestro è più utile al discepolo della propria opinione corretta'), che rinvia a sua volta all'esempio di Mosè e al-Ḩaḍir. Cfr. anche F. Meier, 'Khurāsān', 218.

142 L. Massignon, Essai, 80.

143 Un'interessante visione sintetica del ruolo del libro nelle trasformazioni religiose della prima età moderna, che sottolinea le evoluzioni parallele nei tre monoteismi, in Europa e nell'Impero ottomano, si trova in C. Mayeur-Jaouen, 'Hagiographies'; eadem, 'Saint et sainteté'. Ringrazio l'autrice per avermi permesso di leggere questi due articoli prima della loro pubblicazione. 


\section{BIBLIOGRAFIA}

\section{Fonti primarie}

Averroè, Il trattato decisivo (Faṣl al-maqāl), a cura di M. Campanini, (Milano: Rizzoli, 1994).

Al-Ġazālī, Abū Ḥāmid, al-Munqị̂d min al-ḍalāl, ed. J. Șalība e Kāmil 'Iyād, Beirut: Dār al-Andalus, 1967.

—, Kitāb al-Durra al-fāhira fì kašf culūm al-āhira (La Perle Précieuse), ed. L. Gautier (Amsterdam: Oriental Press, 1974).

—_, Ihyā 'ulūm al-dīn (Cairo: Būlāq, 1289/1873).

Al-Ġazzī, Kamāl al-Dīn, al-Wird al-unsī wa-l-wārid al-qudsī fì tarğamat al-šayh̆ ' Abd al-Giañ al-Nābulusī, Ms. Adīb Nābulusī, coll. privata.

Al-Ǧìilī, ${ }^{\circ} A b d$ al-Karīm, al-Insān al-kāmil fì ma ${ }^{c}$ rifat al-awāhir wa-l$a w \bar{a}^{\supset} i l$ (s.l.: Dār al-fikr, s.d.).

$\longrightarrow$, Marātib al-wuğ $\bar{u} d$ wa-haqūqat kull mawğūd (Cairo: Maktabat alĞandī, s.d.).

Ibn ' Abbād de Ronda, Lettres de direction spirituelle (ar-Rasa $\bar{a}^{\supset} i l$ asSughrā), ed. P. Nwyia (Beirut: Dar el-Machreq, 1974).

Ibn 'Arabī, al-Futūḥāt al-Makkiyya (Beirut: Dār șādir, s.d.)

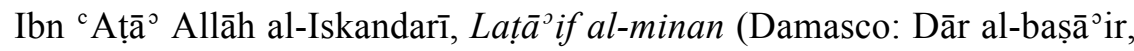
1992).

Ibn Ğamā̄a, Muhammad ibn Ibrāhīm, Tadkirat al-sāmic ${ }^{c}$ wa-lmutakallim fì adab al- ${ }^{c} \overline{a l i m}$ wa-l-mutac ${ }^{c}$ allim, in ${ }^{\mathrm{c}} \mathrm{Abd}$ al-Amīr Šams al-Dīn, al-Fikr al-tarbawī inda Ibn Ğamā ${ }^{c} a$ (Beirut: al-Šarika al${ }^{c}$ ālamiyya li-l-kitāb, 1990), 45-164.

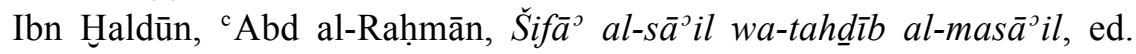
Muhammad Muṭ̣̂ ${ }^{c}$ al-Ḥăfiz (Beirut : Dār al-fikr- Damasco: Dār al-fikr al-mu'āṣir, 1417/1996).

__ La Voie et la loi ou Le maître et le juriste, traduit de l'arabe, présenté et annoté par R. Pérez (Arles: Actes Sud, 2010).

- The Muqaddimah, tr. F. Rosenthal, 2. ed., 3 vol. (London: Routledge, 1967).

Mawlawī, Aḥmad b. Luṭf Allāh [Müneğğim Bāši], Fayḍ al-ḥaram fí $\bar{a} d \bar{a} b$ wa-šarāa $\bar{a}^{\top}$ al-muțālaca, ms. Azhar n. 321741, ff. 1b-26a. http://al-mostafa.info/data/arabic/depot3/gap.php?file=m000507.pdf (accessed 1/28/2012).

Al-Nābulusī, ' Abd al-Ġanī, Raw al al-anām fì bayān al-iğāza fì l-manām, ms. Damasco, Maktabat al-Asad al-Wațaniyya n. 9119, ff. 7a-13a.

_, Kitāb al-rusūh fì maqām al-šuyūh, ms. Berlin We 1631, ff. 187b193b. 
Al-Qušayrī, Das Sendschreiben al-Qušayrīs über das Sufitum, Eingeleitet, übersetzt und kommentiert von Richard Gramlich (Wiesbaden: Franz Steiner, 1989).

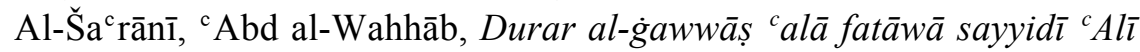
al-Hawwāṣ (Cairo: al-Maktaba al-azhariyya li-l-turāt, s.d.).

_ Lața $\bar{a}^{\mathrm{j}}$ if al-minan wa-l-ahlāq (Cairo: ${ }^{\mathrm{C}} \overline{\mathrm{A}} \mathrm{lam}$ al-fikr, s.d.).

—_, al-Mīzān al-kubrā (Cairo: al-Maṭba ${ }^{\mathrm{c}}$ a al- ${ }^{\mathrm{c}} \bar{A} \operatorname{mira}, 1318$ H.).

Al-Tādifī, Muḥammad ibn Yahyāa, Necklaces of Gems [Qalā̄id alğawāhir fì manāqib al-Šayh ${ }^{c} A b d$ al-Qādir], tr. Muhtar Holland (Hollywood: al-Baz Publishing, 1998. http://www.albaz.com/shaikhabdalqadir/Books_and_Text_of_Wisdom/Qala_id_AlJawahir/8 -Qala id Al-Jawahir $/ \overline{8}$-qala id ${ }_{-}$al-jawahir.htm (accessed $1 / 28 / 2012)$.

Zarrūq, Ahmmad, ${ }^{c}$ Umdat al-murīd al-ṣādiq, ms. Ğāmi ${ }^{\mathrm{c}}$ at al-mālik $\mathrm{Sa}^{\mathrm{c}} \overline{\mathrm{u} d}$ n. 1096; www.al-mostafa.info/data/arabic/depot/gap.php?file=m013336.pdf (accessed 1/28/2012).

—, Qawā $\bar{a}^{c}$ al-tașawwuf (Beirut: Dār al-kutub al- ${ }^{c}$ ilmiyya, 2005).

Zohar, the Book of Enlightenment, tr. D. C. Matt (New York: Paulist Press, 1983).

Fonti secondarie

Adang, C., 'The Spread of Zāhirism in Post-Caliphal al-Andalus: The Evidence from the Biographical Dictionaries', in S. Günther (ed.), Ideas, Images, and Methods of Portrayal. Insights into Classical Arabic Literature and Islam (Leiden: Brill, 2005), 297-346.

Akkach, S., 'Abd al-Ghani al-Nabulusi. Islam and the Enlightenment (Oxford: Oneworld, 2007).

- Letters of a Sufi Scholar. The Correspondence of ${ }^{c} A b d$ al-Ghani al-Nābulusī (1641-1731) (Leiden-Boston: Brill, 2010).

Algar, H., 'The Centennial Renewer: Bediüzzaman Said Nursi and the Tradition of Tajdīd', Journal of Islamic Studies 12/3 (2001), 291-311.

Atiyeh, G.N. (ed.), The Book in the Islamic World: the written word and communication in the Middle East (Albany: State University of New York Press, 1995).

Atlagh, R., 'Le point et la ligne. Explication de la Basmala par la science des lettres chez ${ }^{\mathrm{C}} \mathrm{Abd}$ al-Karīm al-Jīlī (m. 826 H.)', Bulletin des Études Orientales 44 (1992), 161-90.

Ayalon, A., Reading Palestine. Printing and Literacy, 1900-1948 (Austin: University of Texas Press, 2004).

Baldick, J., 'Uwaysiyya,' Encyclopedia of Islam² , x, 958. 
Berkey, J., The Transmission of Knowledge in Medieval Cairo. A Social History of Islamic Education (Princeton: Princeton University Press, 1992).

Bori, C., Ibn Taymiyya: una vita esemplare. Analisi delle fonti classiche della sua biografia, Suppl. 1 a Rivista degli Studi Orientali 76 (PisaRoma, 2003).

Boyarin, D., Border Lines. The partition of Judaeo-Christianity, (Philadelphia: University of Pennsylvania Press, 2004).

Brague, R., 'Athens, Jerusalem, Mecca: Leo Strauss's 'Muslim' Understanding of Greek Philosophy', Poetics Today 19 (1998), 23559.

Chialà, S., 'Les mystiques musulmans lecteurs des écrits chrétiens: quelques échos d'apophtegmes', Proche-Orient Chrétien 60 (2010), 352-67.

Chih, R., C. Mayeur-Jaouen, R. Seesemann, (eds.), Sufism, Literary Production and Printing in the Nineteenth Century (Würzburg: Ergon, in corso di stampa).

Chodkiewicz, M., Le Sceau des saints. Prophétie et sainteté dans la doctrine d'Ibn Arabî (Paris: Gallimard, 1986).

__, Un océan sans rivage. Ibn Arabī, le Livre et la Loi (Paris: Seuil, 1992).

__, 'Rūhāniyya,' $E I^{2}$ viii, 593-4.

—_, 'Note complémentaire sur les rites d'initiation dans les turuq', in Ibn Arabî, Le livre de la filiation spirituelle, a cura di C. Addas, 'Ayn Al-Hayât, Quaderno di studi della Tarîqa Naqshbandiyya, 5 (1999), 45-64.

—, 'Le procès posthume d'Ibn ${ }^{\mathrm{c}}$ Arabī', in De Jong-Radtke (eds.), Islamic Mysticism Contested, 93-123.

—_, 'Mi'rāj al-kalima: de la Risāla Qushayriyya aux Futūhāat Makkiyya', in T. Lawson (ed.), Reason and Inspiration in Islam, 24861.

Coccia, E., La trasparenza delle immagini. Averroè e l'averroismo (Milano: Bruno Mondadori, 2005).

Cook, M., 'On the Origins of Wahhabism', Journal of the Royal Asiatic Society 2 (1992), 191-202.

Cook, M., Commanding Right and Forbidding Wrong in Islamic Thought (Cambridge: Cambridge University Press, 2000).

Cornell, V., Realm of the Saint. Power and Authority in Moroccan Sufism (Austin: University of Texas Press, 1998). 
Cornell, V., 'Faqīh versus Faqīr in Marinid Morocco: Epistemological Dimensions of a Polemic', in De Jong and Radtke (eds.), Islamic Mysticism Contested, 207-24.

De Jong, F., Radtke, B. (eds.), Islamic Mysticism Contested: Thirteen Centuries of Controversies and Polemics (Leiden-Boston: Brill, 1999).

Dickinson, E., 'Ibn al-Ṣalāh al-Shahrazūrī and the Isnād', Journal of the American Oriental Society 122 (2002), 481-505.

Elmore, G.T., 'New Evidence on the Conversion of Ibn Al- ${ }^{\mathrm{c}} \mathrm{Arab} \overline{1}$ to Șūfism', Arabica 45 (1998), 50-72.

_, Islamic Sainthood in the Fullness of Time. Ibn al- 'Arabi's Book of the Fabulous Gryphon (Leiden: Brill, 1999).

Ernst, C.W., 'Mystical Language and the Teaching Context in the Early Lexicons of Sufism', in S.T. Katz (ed.), Mysticism and Language (New York: Oxford University Press, 1992), 181-201.

Fierro, M., 'Opposition to Sufism in al-Andalus', in De Jong-Radtke (eds.), Islamic Mysticism Contested, 174-206.

Frank, K.S., 'Fiktive Mündlichkeit als Grundstruktur der monastichen Literatur', in C.M. Kasper, K. Schreiner (eds.), 'Viva vox und ratio scripta'. Mündliche und schriftliche Kommunikationsformen im Mönchtum des Mittelalters (Münster: LIT, 1997), 51-74.

Geoffroy, É., Le soufisme en Égypte et en Syrie sous les derniers Mamelouks et les premiers Ottomans. Orientations spirituelles et enjeux culturels (Damas: Ifead, 1995).

_, (ed.), La Shadhiliyya. Une voie soufie dans le monde (Paris: Maisonneuve-Larose, 2005).

_, 'Entre ésotérisme et exotérisme, les Shādhilis, passeurs de sens (Égypte, $\mathrm{XIII}^{\mathrm{e}}-\mathrm{XV}^{\mathrm{e}}$ siècles)', in Geoffroy, (ed.), La Shadhiliyya, 11732.

Ghersetti, A., 'L'utilità della scrittura e la lode del libro: testimonianze di alcuni scrittori arabi medievali', Annali di Ca' Foscari XXXIII, 3, s.o. 25 (1994), 67-76.

Gianotti, T.J., Al-Ghazālī's Unspeakable Doctrine of the Soul. Unveiling the Esoteric Psychology and Eschatology of the Ihy $\bar{a}^{\supset}$ (Boston: Brill, 2001).

Gil'adi, A., 'On the Origin of Two Key-Terms in al-Gazzālî̀s Ihya ${ }^{\supset}$ 'Ulüm al-Dìn', Arabica 36 (1989), 81-92.

Goldziher, I., The Zāhirīs. Their Doctrine and their History, tr. W. Behn (Leiden: Brill, 2008). 
Graham, W.A., Beyond the Written Word: Oral Aspects of Scripture in the History of Religion (Cambridge: Cambridge University Press, 1987).

Griffel, F., Apostasie und Toleranz im Islam. Die Entwicklung zu alGazālīs Urteil gegen die Philosophie und die Reaktionen der Philosophen (Leiden: Brill, 2000).

-, al-Ghazālì's Philosophical Theology (Oxford: Oxford University Press, 2009).

Gril, D., 'Le saint fondateur', in A. Popovic et G. Veinstein (eds.), Les Voies d'Allah (Paris: Fayard, 1996), 104-20).

—_, 'L'enseignement d'Ibn 'Atā' Allāh al-Iskandarī, d'après le témoignage de son disciple Rāfic ${ }^{c}$ Ibn Shāfic', in Geoffroy, (ed.), $L a$ Shadhiliyya, 93-106.

- 'De la khirqa à la tarīqa. Continuité et évolution dans l'identification et la classification des voies', in R. Chih, D. Gril, C. Mayeur-Jaouen (eds.), Le soufisme en Egypte et dans le monde musulman à l'époque ottomane (Cairo: Institut Français d'Archéologie Orientale, 2010), 57-81.

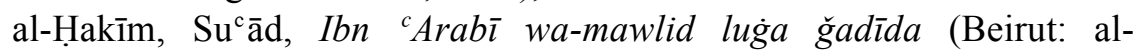
$\mathrm{Mu}^{\mathrm{D} a s s a s a}$ al-ğāmic iyya li-1-dirāsāt wa-1-našr wa-l-tawzī̄ $\left.{ }^{\mathrm{c}}, 1991\right)$.

Halbertal, M., 'From Oral Tradition to Literary Canon: Shem Tov Ibn Gaon and the Critique of Kabbalistic Literature', in M. Finkelberg G.G. Stroumsa (eds.), Homer, the Bible, and Beyond: Literary and Religious Canons in the Ancient World (Boston: Brill, 2003), 253-65.

_- Concealment and Revelation. Esotericism in Jewish Thought and Its Philosophical Implications (Princeton and Oxford: Princeton University Press, 2007).

Hartmann, A., An-Nāṣir li-Dīn Allāh (1180-1225). Politik, Religion, Kultur in der späten 'Abbāsidenzeit (Berlin-New York: Walter de Gruyter, 1975).

Idel, M., Kabbalah. New Perspectives (New Haven and London: Yale University Press, 1988).

Karamustafa, A.T., Sufism. The Formative Period, Edinburgh: Edinburgh University Press, 2007.

Kinberg, L., 'Dreams as a Means to Evaluate Hadīth', Jerusalem Studies in Arabic and Islam 23 (1999), 79-99.

Knysh, A., Ibn 'Arabi in the Later Islamic Tradition. The Making of a Polemical Image in Medieval Islam (New York: SUNY, 1999).

Kramers, J.H., 'Münedjdjim Bāshi,' $E I^{2}$, vii, 572-3.

Kugle, S., 'Usūlī Sufis: Ahmad Zarrūq and his South-Asian Followers', in Geoffroy (ed.), La Shadhiliyya, 181-201. 
Kugle, S., Rebel between Spirit and Law: Ahmad Zarruq, Sainthood, and Authority in Islam (Bloomington: Indiana University Press, 2006).

Landi, S., 'Stampa, censura e governo delle opinioni', in Storia d'Europa e del Mediterraneo, sezione quinta: L'età moderna, a cura di Roberto Bizzocchi (Roma: Salerno, 2011), 49-83.

Landolt, H., Correspondance spirituelle échangée entre Nuroddin Esfarayeni (ob. 717/1317) et son disciple 'Alaoddawleh Semnani (ob. 736/1336), texte persan publié avec une introduction par H. Landolt (Teheran-Paris: Institut franco-iranien de recherche-Maisonneuve, 1972).

, 'Der Briefwechsel zwischen Kāšānī und Simnānī über Wahdat alWuğùd', Der Islam 50-1 (1973), 29-81.

Lawson, T. (ed.), Reason and Inspiration in Islam. Essays in Honour of Hermann Landolt (London: Tauris, 2005).

Madigan, D.A., The Qur'ân's Self-Image. Writing and Authority in Islam's Scripture (Princeton and Oxford: Princeton University Press, 2001).

Mahdi, M., 'The Book and the Master as Poles of Cultural Change in Islam', in Speros Vryonis Jr. (ed.), Islam and Cultural Change in the Middle Ages [Fourth Giorgio Levi Della Vida Biennal Conference, May 11-13 1973, UCLA], Wiesbaden: Harrassowitz 1975), 3-15.

Malamud, M., 'Sufi organizations and structures of authority in medieval Nishapur', International Journal of Middle East Studies 26 (1994), 427-42.

Mallet, D., 'Les livres de Ḥayy', Arabica 44 (1997), 1-34.

Mansiyya, M., 'Al-Iğtihād kamā yarāhu Ibn 'Arabī', in Qadiyyat aliğtihād fi l-fikr al-islāmī, Cahiers du C.E.R.ES.: série civilisation arabo-islamique (Tunis) 1 (1987), 125-46.

Massignon, L., Essai sur les origines du lexique technique de la mystique musulmane (Paris: Vrin, 1954).

_ L La Passion de Husayn Ibn Mansūr Hallāj (Paris: Gallimard, 1975).

Mayeur-Jaouen, C., 'Hagiographies, quête mystique et tentation de l'autobiographie dans la culture religieuse arabe (XVe-XIXe siècle)', in François-Joseph Ruggiu (dir.),. Les usages de l'écrit du for privé (Afriques, Amériques, Asies, Occidents, Orients), Actes du colloque tenu à 1'Université de Paris-Sorbonne 28 juin-2 juillet 2011 (Paris: Peter Lang, in corso di stampa).

_ _ 'Saint et sainteté: un idéal?', in Dionigi Albera et Katell Berthelot (dir.), Dictionnaire des monothéismes (Paris: Flammarion, in corso di stampa). 
Meier, F., Essays on Islamic Piety and Mysticism, tr. J. O'Kane (Leiden: Brill, 1999).

_, 'Qusăyrī's Tartīb as-sulūk', in Meier, F., Essays on Islamic Piety and Mysticism, 93-134.

, 'Khurāsān and the end of classical Sufism', in Meier, F., Essays on Islamic Piety and Mysticism, 189-218.

, 'An Exchange of Letters between Sharaf al-Dīn-i Balkhī and Majd al-Dīn-i Baghdādī', in Meier, F., Essays on Islamic Piety and Mysticism, 245-82.

Melchert, C., The Formation of the Sunni Schools of Law, 9th-10th Centuries C.E. (Leiden: Brill, 1997).

Moosa, E., Ghazālì and the Poetics of Imagination (Chapel Hill: The University of North Carolina Press, 2005).

Morris, J.W., 'Ibn 'Arabi's 'Esotericism': The Problem of Spiritual Authority', Studia Islamica 71 (1990), 37-64.

_ , 'An Arab Machiavelli? Rhetoric, Philosophy and Politics in Ibn Khaldun's Critique of Sufism', Harvard Middle Eastern and Islamic Review 8 (2009), 242-91.

Nasr, S.H., 'Oral Transmission and the Book in Islamic Education', in Atiyeh (ed.), The Book in the Islamic World, 57-70.

Neuwirth, A., Der Koran als Text der Spätantike: ein europäischer Zugang, (Berlin: Verlag der Weltreligionen, 2010).

Nichloson, R.A., Studies in Islamic Mysticism (Richmond: Curzon, 1994).

Nwyia, P., Ibn 'Abbād de Ronda (1332-1390) (Beyrouth: Imprimerie Catholique, 1961).

Ogren, B., Renaissance and Rebirth. Reincarnation in Early Modern Italian Kabbalah (Leiden-Boston: Brill, 2009).

Ohlander, E., Sufism in an Age of Transition. 'Umar al-Suhrawardī and the Rise of the Islamic Mystical Brotherhoods (Leiden-Boston: Brill, 2008).

Pagani, S., Il rinnovamento mistico dell'Islam. Un commento di ' ${ }^{c} A b d$ alGhan̄i al-Nābulusī a Aḥmad Sirhind̄̄ (Napoli: Istituto Universitario Orientale, 2003. Dissertationes III).

- 'Scholasticism and Sufi tradition. The transmission of the Naqshbandi tariqa between Central Asia, India and the Ottoman Empire', in Italo-Uzbek Scientific Cooperation in Archaeology and Islamic Studies: An Overview. Rome, January 30, 2001, ed. by S. Pagani (Roma: Istituto Italiano per l'Africa e l'Oriente, 2003), 26988. 
Pagani, S., 'The meaning of the ikhtilāf al-madhāhib in 'Abd al-Wahhāb al-Sha' rānī's al-Mīzān al-kubrä', in Islamic Law and Society 11 (2004), 177-212.

Pérez, R., 'Introduction', in Ibn Khaldūn, La voie et la loi, 11-92.

Piemontese, A.M., 'Sistema e strumenti dell'Islam', in R.-H. Bautier e A.M. Piemontese, La comunicazione nella storia. Lo sviluppo del pensiero e le forme del comunicare. Medioevo. Islam (Roma: STET, 1992, 285-386).

al-Qāḍ̄ (Kadi), Wadād, 'Scholars and Their Books: A Peculiar Islamic View from the Fifth/Eleventh Century', Journal of the American Oriental Society 124 (2004), 627-40.

Radtke, B., 'The Eight Rules of Junayd: A General Overview of the Genesis and Development of Islamic Dervish Orders', in Lawson (ed.), Reason and Inspiration in Islam, 490-502.

Radtke, B., O'Kane, J., The Concept of Sainthood in Early Islamic Mysticism (Richmond: Curzon, 1996).

Richter-Bernburg, L., 'Ibn al-Māristānīya: The Career of a Hanbalite Intellectual in Sixth/Twelfth Century Baghdad', Journal of the American Oriental Society 102 (1982), 265-83.

Rippin, A., Muslims. Their religious beliefs and practices, 3 ed. (London: Routledge, 2005).

Rosenthal, F., The Technique and Approach of Muslim Scholarship (Roma: Pontificium Institutum Biblicum, 1947).

_ , "Of Making Many Books There is no End': The Classical Muslim View', in Atiyeh (ed.), The Book in the Islamic World, 33-56.

_, 'Ibn 'Arabī between 'Philosophy' and 'Mysticism', Oriens 31 (1988), 1-35.

Saenger, P., Space Between Words: The Origins of Silent Reading (Stanford: Stanford University Press, 1997).

Safi, O., The Politics of Knowledge in Premodern Islam (Chapel Hill: The University of North Carolina Press, 2006).

Sartain, E.M., Jalāl al-Dīn al-Suyūṭ̂̀ (Cambridge: Cambridge University Press, 1975).

Schimmel, A., Die Träume des Kalifen: Träume und ihre Deutung in der islamischen Kultur (München: Beck, 1998).

Silvers-Alario, L., 'The Teaching Relationship in Early Sufism: A Reassessment of Fritz Meier's Definition of the shaykh al-tarbiya and the shaykh al-ta'lim', Muslim World 93 (2003), 69-97.

Stock, B., Listening for the Text. On the Uses of the Past (BaltimoreLondon: John Hopkins University Press, 1990). 
Strauss, L., Persecution and the Art of Writing (New York: Free Press, 1952).

Sviri, S., 'Kun - the Existence-bestowing Word in Islamic Mysticism: A Survey of Texts on the Creative Power of Language', in S. La Porta D. Shulman (eds.), The Poetics of Grammar and the Metaphysics of Sign and Sound (Leiden: Brill, 2007), 35-67.

Szombathy, Z., 'Freedom of Expression and Censorship in Medieval Arabic Literature', Journal of Arabic and Islamic Studies 7 (2007), 1-24.

ter Haar, J.,'The Importance of the Spiritual Guide in the Naqshbandī Order', in L. Lewisohn (ed.), The Legacy of Mediaeval Persian Sufism (London-New York: Khaniqahi Nimatullahi Publications, 1992), 311-22.

Vajda, G., 'Idjāza', $E I^{2}$ iii, 1020-2.

von Schlegell, B.R., Sufism in the Ottoman Arab World: Shaykh ' Abd alGhan̄ al-Nābulusì (d. 1143/1731), Ph.D. dissertation (Berkeley: University of California, 1997).

Wolfson, E., 'Beyond the Spoken Word: Oral Tradition and Written Transmission in Medieval Jewish Mysticism', in Y. Elman, I. Gershoni (eds.), Transmitting Jewish tradition: Orality, Textuality and Cultural Diffusion (New Haven: Yale University Press, 2000, 166224).

-, 'The Body in the Text: A Kabbalistic Theory of Embodiment', The Jewish Quarterly Review 95 (2005), 479-500. 